Yr Adran Plant, Addysg, Dysgu Gydol Oes a Sgiliau

Department for Children, Education, Lifelong Learning and Skills

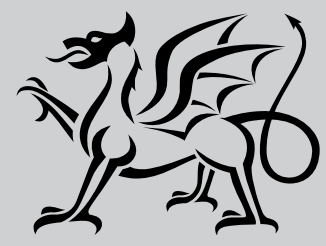

Llywodraeth Cynulliad Cymru Welsh Assembly Government

\title{
Student Withdrawal from Higher Education
}

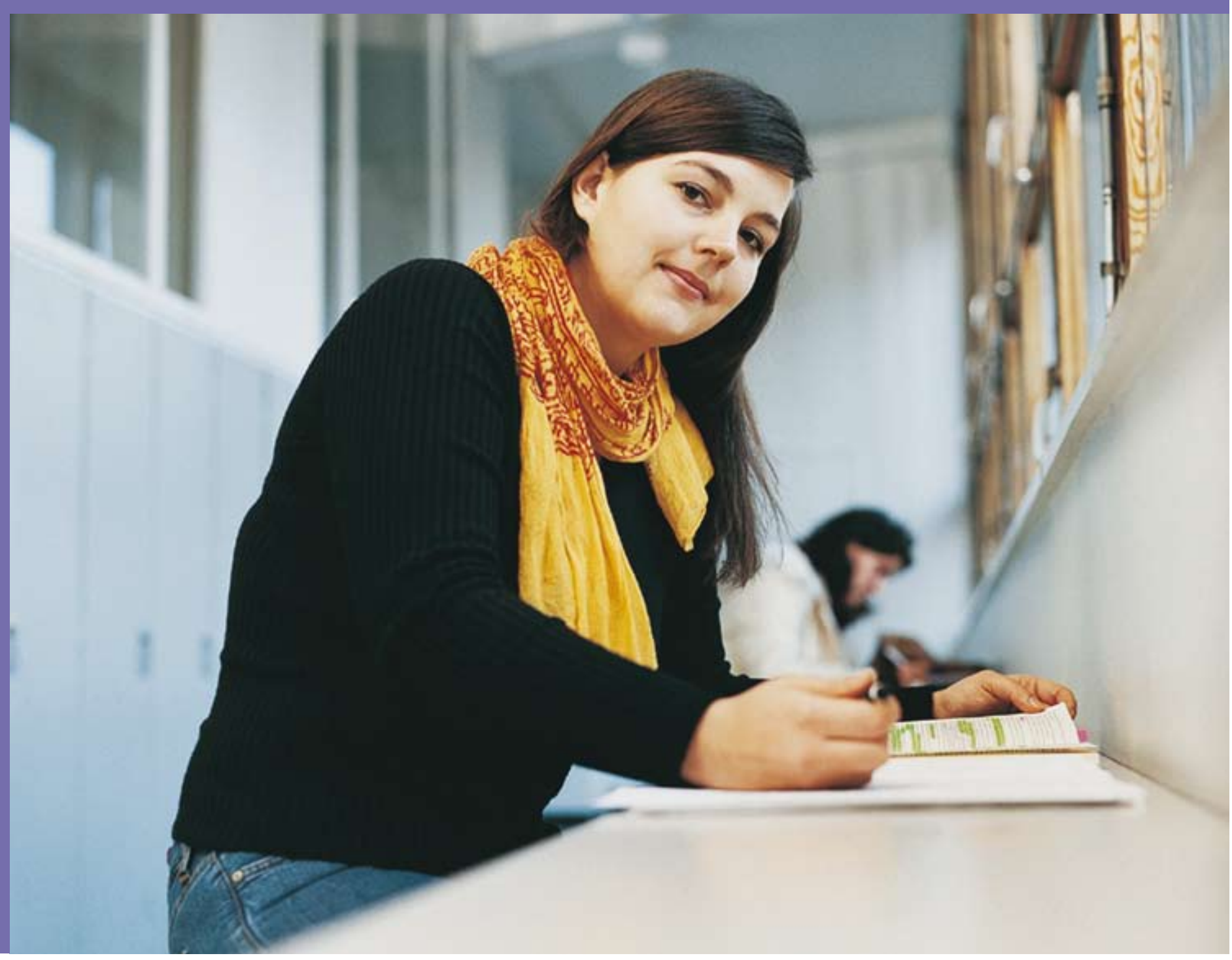

Research

Research document No: 042/2009

Date of issue: August 2009 


\section{Student Withdrawal from Higher Education}

Audience National and local bodies in Wales concerned with education, training and skills in Wales.

Overview The Department for Children, Education, Lifelong Learning and Skills (DCELLS) strategy document, The Learning Country: Vision into Action states that DCELLS will "...consider... how best to monitor the views of students on a regular basis and to publish the results". This report covers the findings of a literature review of student withdrawal in Higher Education. This report contributes to the wider Customer Research Programme 2007-10.

Action None - for information.
required

Further Julie Owens

information Senior Research Analyst

Research and Evaluation Branch

Knowledge Management Division, DCELLS

Welsh Assembly Government

Unit 6, St. Asaph Business Park

St. Asaph, Denbighshire

LL17 OLJ

Tel: 01745538540

Fax: 01745538501

E-mail: Research2@wales.gsi.gov.uk

Additional Can be obtained from Julie Owens at the address above or by copies visiting the Welsh Assembly Government website http://wales.gov.uk/topics/educationandskills/ research-and-evaluation/customer-research

\section{Related None. \\ documents}




\title{
Student Withdrawal from Higher Education
}

\author{
A report prepared by
}

Maguire Policy Research
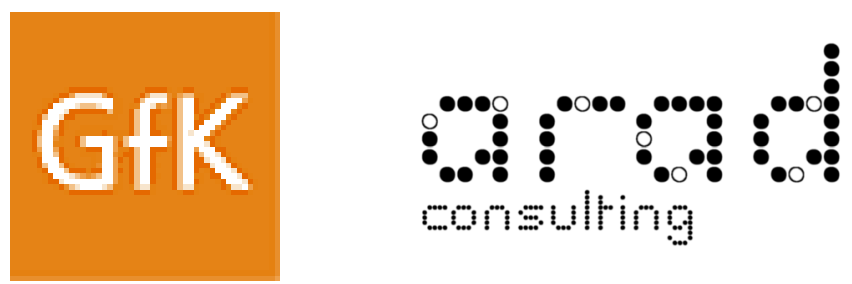

min

On behalf of the Department for Children Education Lifelong Learning and Skills of the Welsh Assembly Government

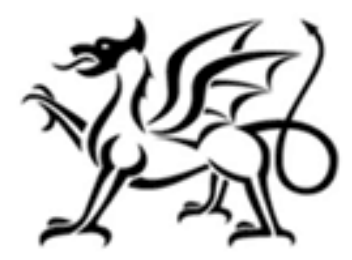

Llywodraeth Cynulliad Cymru Welsh Assembly Government

May 2009 


\section{Contents}

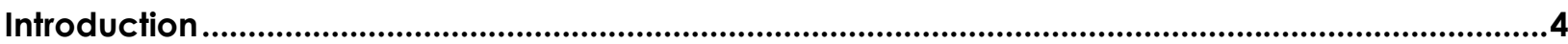

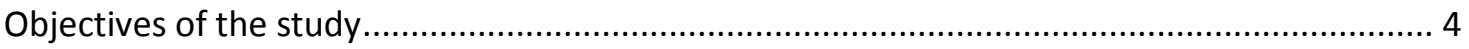

Terminology

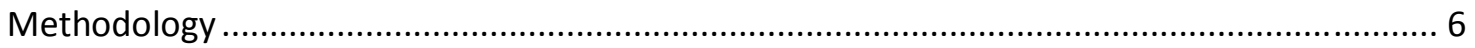

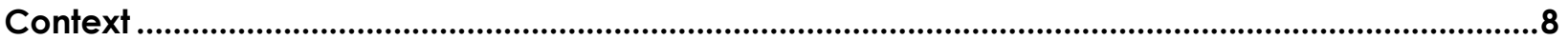

Characteristics of students at Welsh HEls ..................................................................... 11

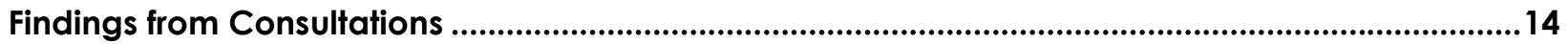

Student withdrawal and non-completion ......................................................................... 14

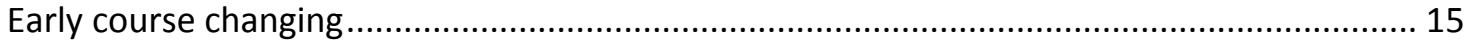

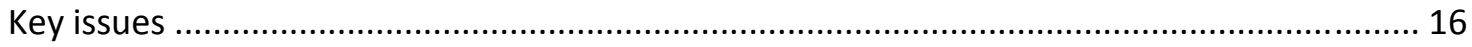

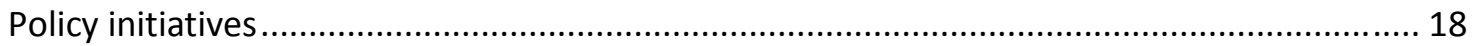

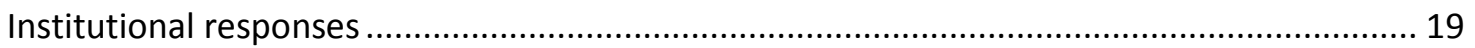

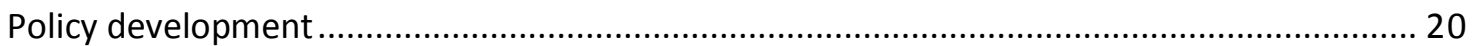

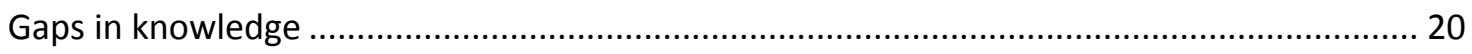

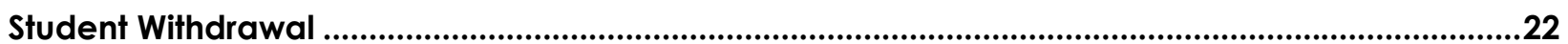

Completion and continuation rates ............................................................................. 22

Characteristics of non-continuing students ..................................................................... 26

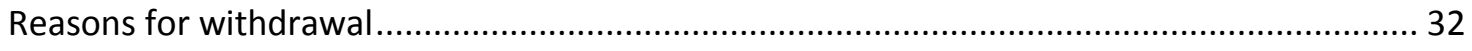

Common reasons for students' withdrawal from courses ................................................. 35

Factors affecting students' decision to withdraw .............................................................. 37

When withdrawal occurs................................................................................................... 41

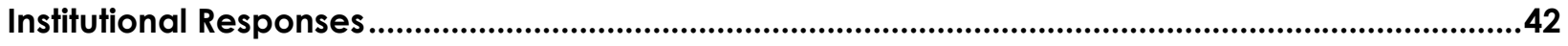

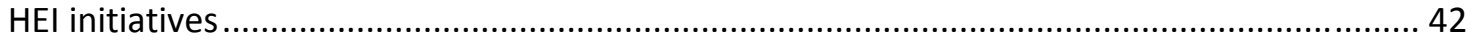

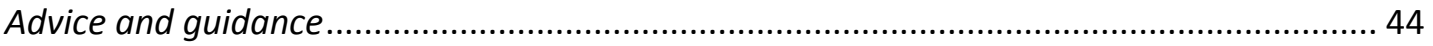

Conclusions and Recommendations ............................................................................................47

Implications for further CRP 2007-2010 research................................................................ 49 
1. Remit and scope of department/branch/organisation.....

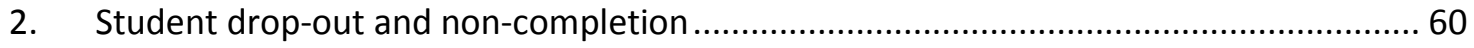

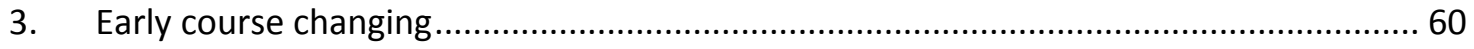

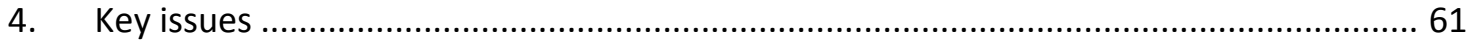

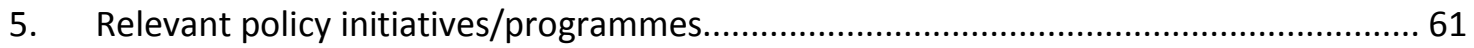

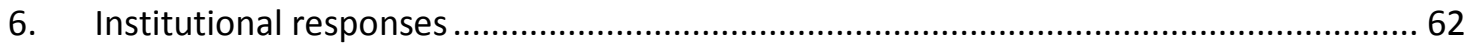

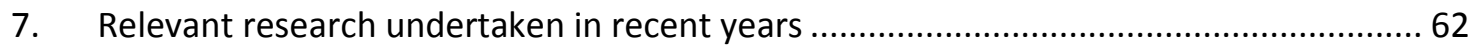

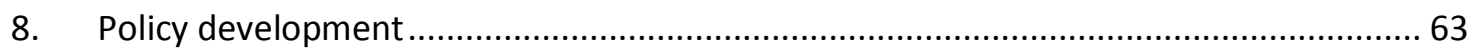

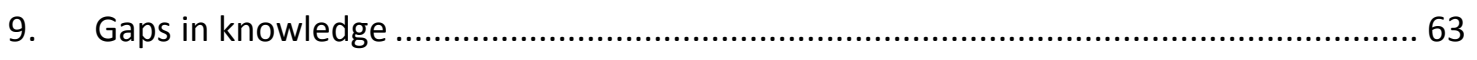

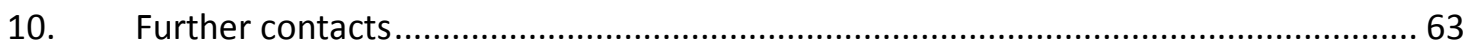

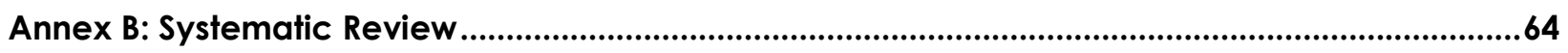




\section{Introduction}

The Department for Children, Education, Lifelong Learning and Skills (DCELLS) has established a programme of customer research to provide a knowledge base to develop a clear understanding of its markets, customers and potential customers. It is essential that DCELLS has this evidence in order develop "citizen centred services", as part of the Making the Connections and Beecham agendas. The aims of the programme are:

- to understand what motivates customers to learn in order to widen and deepen participation in learning

- to understand what customers think of the education and learning services they receive

- to identify the learning needs of people

GfK NOP, in association with Maguire Policy Research and Arad Consulting, was commissioned to undertake this three year programme of customer research on behalf of DCELLS.

During the consultations as part of the inception phase of the Customer Research Programme (CRP) 2007-2010, the issue of people who dropped out of learning was mentioned as one which was worthy of study across all areas of learning, irrespective of where it was delivered (FE, HE, WBL, ACL etc). In particular, the need to gain a better understanding of the reasons for withdrawal and the factors affecting the decisionmaking process was frequently stated. This report presents the findings of a literature review of student withdrawal from Higher Education (HE)

\section{Objectives of the study}

The overall objective of this study was to undertake a systematic literature review which would inform and underpin subsequent empirical research among Welsh Higher Education Institutions (HEls). It was felt to be important not to duplicate previous research or to commit resources to investigating issues about which there was already a substantial body of evidence and knowledge. Rather, a key objective was to identify areas about which little was known, and where investigation would enhance knowledge and understanding and inform policy. 


\section{Terminology}

At the outset, it is worth mentioning the different terminology used for what the title of the study refers to as 'student withdrawal'. From a student perspective, 'drop out' is commonly used, while from a Higher Education Institution (HEI) perspective, the issue is usually referred to as 'student retention'. As Yorke (2003: p 1) suggests, for both HEls and policy-makers, economic considerations can underlie their concern over student retention.

"Retention is a 'supply-side' concept, for understandable supply-side reasons. It is a concept that is important for institutional managers (not least because of the implications for income streams) and for government and its agencies (which are concerned with matters relating to the return on the investment of public monies in higher education)."

(Yorke, M. (2003) Why students leave early in higher education in the UK)

Other frequently cited terms to describe the phenomenon of students choosing to curtail their studies include 'non-retention', 'failing to progress', 'non-continuation' and 'noncompletion'. Morgan (undated) adds 'departure', 'unsuccessful' and 'failed' to this list, and points out that Leys (1999) suggested there were "nine definitions associated with drop-out or withdrawal", while Foster (2000) had identified thirteen possible definitions.

Morgan goes on to discuss some pertinent dimensions which are not fully encapsulated in any of these definitions, the main ones being:

- A distinction between withdrawal/dropping out from a particular course or $\mathrm{HEl}$, and leaving $\mathrm{HE}$ altogether. The issue raised here is whether the student who is classified in the statistics as having withdrawn has done so in order to switch to a course and/or HEI which they deem more appropriate, or whether they have withdrawn from HE completely;

- Whether a student's withdrawal/departure has been a voluntary decision or whether it resulted from a failure to meet the standards and requirements of a course.

As far as official statistics are concerned, the Higher Education Statistics Agency (HESA), which produces performance indicators on behalf of the HE funding councils for each of the four home countries, including the Higher Education Funding Council for Wales (HEFCW), provides figures relating to 'non-continuation following year of entry' and 'non-completion' figures, which are based on projections of patterns of student outcomes over fifteen years.

The focus of this literature review is students who embark on first degree courses, but take the decision to withdraw from the course, for whatever reason, before completing the course of study. Therefore, it is not intended to encompass those students whose non-continuation is due to their failure to meet the requirements of the course. 


\section{Methodology}

The approach to this literature review was based on the Systematic Review process advocated by the Evidence for Policy and Practice Information and Co-ordinating Centre (EPPI-Centre) at the Social Science Research Unit of the Institute of Education, University of London. A key component of this approach is that the methodology to be adopted is made explicit, with the parameters of the study clearly stated and the criteria by which evidence is deemed appropriate for inclusion defined at the outset. A 'protocol' is developed to ensure that this is done prior to embarking on the process of gathering evidence. Annex $B$ describes the protocol which framed the current study.

The study comprised three main strands:

1. Consultations with key stakeholders

2. Desk research

3. Additional contacts

\section{Consultations}

The purpose of the consultations was to gain the perspectives of policy-makers and key stakeholders on what should constitute the focus of the literature review. In particular, their perceptions of the most significant factors to be addressed in considering student withdrawal, and their relationship to current and future policy options was needed in order to ensure that the study would be relevant and informative.

In addition, the consultations sought to: identify any relevant reports or publications which should be included in the review; determine whether there were any significant current or projected research which could be pertinent; and gain contact details for individuals and/or bodies and institutions which would be able to provide further information.

Face-to-face consultations were held with the following respondents:

- Lisa Newberry - DCELLS Higher Learning group

- Jane Johns and Celia Hunt - HEFCW

- Karen Jones - Higher Education Wales

- Jo Roberts - National Union of Students Wales

- Ben Lewis - Head of Student Advisory Services at Cardiff University

- Helen James - Director of Higher Education Strategy and Further Education Development at North East Wales Institute of Higher Education (NEWI).

The semi-structured topic guide used for the consultations is found in Annex A.

\section{Desk research}


The main task of the desk research was to undertake a search of literature relating to student withdrawal from $\mathrm{HE}$ and course changing among new entrants. Initially, the search strategy focused on publications from key organisations, such as:

- Higher Education Funding Council for Wales (HEFCW)

- Higher Education Funding Council for England (HEFCE)

- Higher Education Statistics Agency (HESA)

- Association of Graduate Careers Advisory Services (AGCAS)

- Society for Research in Higher Education (SRHE)

- Institute for HE Policy

- Council for Industry and Higher Education (CIHE)

- Open University Knowledge Network

At the same time, key databases, such as that for the Current Educational Research in the United Kingdom (CERUK) and the EPPI Database for Educational Research were trawled.

Thereafter, the academic journals, such as: Higher Education Quarterly; Higher Education Policy; Education Research; Higher Education Review; Further and Higher Education; British Journal of Guidance and Counselling; Journal of Further and Higher Education; Studies in Higher Education; and Welsh Journal of Education, were explored.

The framework within which the examination of the literature took place was geared to the following broad headings:

- Trends in withdrawal and course changing - distribution across HEls in Wales and comparisons with other parts of the UK

- Characteristics of those who withdraw and/or change course

- Reasons for withdrawal and/or changing course, and factors affecting students' decision-making

- Institutional responses and advice and guidance for students

A list of the references identified and consulted is provided at the end of the report.

\section{Additional contacts}

In addition to the stakeholders who were consulted face-to-face, email contact was made with: Margaret Dane, Chief Executive of the Association of Graduate Careers Advisory Services (AGCAS); and Jane Artess, Research Director, Higher Education Careers Service Unit (HECSU). The purpose of these contacts was to to be alerted to the existence of current and upcoming studies of student withdrawal.

Also, published material, in the form of data or written reports, which could contribute to the study, was sought from Universities UK (UUK) and the Standing Conference of Principals (SCOP. 


\section{Context}

Before embarking on a discussion of the literature relating to student withdrawal from $\mathrm{HE}$ in Wales, it is necessary to be reminded of the policy context in which this phenomenon occurs and to be aware of the characteristics of students attending Welsh HEls, and how those characteristics compare to students at HEls in other parts of the United Kingdom.

\section{Policy context}

As far as overall policy is concerned, the most relevant for this discussion are: the widening participation agenda; the Reaching Higher initiative; the Reaching Wider initiative; and the role of tuition fees.

\section{Widening participation}

Recent years have seen significant increases in participation rates in higher education throughout the United Kingdom. This trend has been encouraged by the introduction of a widening access and participation agenda, which has contributed to the growing numbers of students entering HE from groups which have traditionally been underrepresented. The Teaching and Learning Research Programme (TLRP), which is jointly funded by the Higher Education Funding Council for England (HEFCE) and the Economic and Social Research Council (ESRC), provided the following detailed definition of widening participation.

"Widening participation is taken to mean extending and enhancing access to HE experiences of people from so-called under-represented and diverse subject backgrounds, families, groups and communities and positively enabling such people to participate in and benefit from HE. People from socially disadvantaged families and/or deprived geographical areas, including deprived remote, rural and coastal areas or from families that have no prior experience of HE may be of key concern. Widening participation is also concerned with diversity in terms of ethnicity, gender, disability and social background in particular HE disciplines, modes and institutions. It can also include access and participation across the ages, extending conceptions of learning across the life-course, and in relation to family responsibilities, particularly by gender and maturity"

(quoted in Watson, 2006)

More succinctly, HEFCW describes widening access as being about "increasing opportunities for people from a diverse range of backgrounds to benefit from higher education" (HEFCW website).

As Watson (2006) states, "at its heart ... widening participation is an issue of social justice. More concretely, succeeding at it contributes to social cohesion" (Watson, 2006: $\mathrm{p} 2$ ). At the same time, concerns have been raised about potential increases in rates of student drop-out (Watson, 2006: p 3). Thus, the impact of widening participation on the 
characteristics of the student body in HE needs to be borne in mind when considering student withdrawal.

\section{Reaching Higher}

Reaching Higher (Welsh Assembly Government, 2002) is the national strategy for higher education. The strategy was published in 2002, and set out plans to 2010 to make higher education in Wales "an inclusive and world-renowned sector". It acknowledged the Welsh HE sector's strong record in attracting and retaining students from disadvantaged and under-represented backgrounds, while noting that "too many people who could potentially benefit from HE still believe that higher education is not for them". There was a specific commitment to work with Communities First areas, in conjunction with the Higher Education Funding Council for Wales (HEFCW).

Moreover, the document recognised a need to address the issue of student retention, with particular emphasis on the role of support and career advice:

"Retention is as important as recruitment. Widening access to those who were traditionally under represented in higher education brings new challenges for student retention. These groups frequently need higher levels of support than has traditionally been available. We believe that institutions need to adopt a still more learner centred approach ... HEls need to ensure that pastoral support and guidance is available to students many of whom will be living away from home for the first time. That support needs to be tailored to their specific, individual needs, including any special needs that they may have. This should be the start of lifelong contacts with students, embracing the highest standard of career advice, including advice on career opportunities in Wales, and an active alumni service."

(Welsh Assembly Government, 2002: pp 9-10)

The current Reaching Higher strategy is scheduled to end in 2010 , and on June $25^{\text {th }}$ 2008, the Education Minister, Jane Hutt, announced that a two-stage review of higher education in Wales was to be instigated. The first stage of the review, to be completed by the end of September 2008, focused on student finance arrangements, with particular reference to how they align with attempts to widen access. The purpose of the second stage, was to review "the mission, purpose and role for higher education in Wales taking account of the vision set in Reaching Higher and Skills that Work for Wales". 


\section{Reaching Wider}

In Wales, the 'Widening Access' agenda focuses on four target groups, namely those from Communities First Areas, those from BME groups, those studying through the medium of Welsh and those with disabilities. During recent years, policy at institution level and at regional level (e.g. through the 'Reaching Wider' partnerships) has increasingly targeted retention and support, as well as widening access through recruitment from schools and colleges.

The Reaching Wider initiative was established to fulfil the commitment to providing greater access to higher education for people with characteristics and backgrounds which have not traditionally been well-represented in HE. In order to oversee the implementation of the initiative, as well as to administer the allocation of funding, four regional Reaching Wider Partnerships were established in: North Wales; West and Mid Wales; South West Wales; and South East Wales.

The four target groups identified in Reaching Higher for the Reaching Wider policy initiative were:

- Individuals from Communities First areas

- Black and other ethnic minority groups

- Disabled people

- Welsh speakers

\section{Tuition fees}

In England, the introduction of tuition fees and a system of student loans has been associated with changes in the behaviour of HE students (Adnett, 2006). As well as leading to a significant increase in the propensity of students to engage in employment during term time (Metcalf, 2005), it has been suggested that the role of tuition fees has contributed to changes in the probability of students withdrawing from HE (Davies and Elias, 2003).

In Wales, the student finance system which operates in higher education differs from that in England (Rees and Taylor, 2006). The Welsh Assembly decided against introducing top-up fees at the same time as in England. When they did so, in autumn 2007 , the fee of $£ 3,000$ a year could be offset for Welsh students who study in Wales by a $£ 1,800$ tuition fee grant from the Welsh Assembly. Rees and Taylor point to there being much larger flows of students into and out of Wales than is found in the rest of the UK. However, "from 2007-2008, there will be a significant price differential for Welshdomiciled students studying in Wales and those who wish to go elsewhere" (Rees and Taylor, 2006). In relation to the widening access agenda, Rees and Taylor conclude that fees do not constitute an issue of overarching importance.

In the review of higher education in Wales mentioned above, the first stage focused on student finance and considered the issue of graduate debt and the potential role of 
national statutory student finance and locally delivered bursaries, scholarships etc. The report of the Rees Review of student funding in Wales (Rees et al, 2005) advocated the introduction of a national bursary scheme, which would provide targeted assistance for students, especially those from lower income families. Thus, there was a desire to assist the widening access agenda and to provide an incentive for Welsh-domiciled students to study in Wales.

As will be seen later, the issues of, firstly, income and, secondly, the difficulties experienced by students from socio-economic groups which have traditionally not participated in higher education, are prominent in the list of factors which are felt to contribute to student withdrawal.

\section{Characteristics of students at Welsh HEls}

On the premise that certain factors, especially relating to the characteristics of groups of $\mathrm{HE}$ entrants, are associated with the likelihood of withdrawal from HE, it is necessary to establish the characteristics of the student population in Welsh HEls. In particular, it is important to place any comparisons between students in Wales and those in the other home countries in the context of differences in the respective student populations. The following discussion draws on Higher Education Statistics Agency (HESA) data, and reveals significant differences between HEls in Wales and those in the rest of the United Kingdom, in the characteristics of annual cohorts of HE entrants.

Firstly, as far as the proportion of young entrants to full-time first degree courses from state schools or colleges is concerned, the figures from six intakes up to 2006/07 show that those for Wales were consistently higher than those for England and Scotland by around 5 to 6 percentage points over successive cohorts (Table 1). This has implications for retention rates, as those from state schools exhibit a greater likelihood than those from non-state schools of withdrawing from HE. It can be seen that the gap between the figure for Wales and that for England grew by one percentage point from $2005 / 06$ to $2006 / 07$. 


\section{Table 1 - Percentage of young entrants to full-time first degree courses from state schools}

\begin{tabular}{|c|c|c|c|c|c|c|}
\hline Proport & young (ag & under 21) & rants to fu & ime first de & $\begin{array}{l}\text { ee course } \\
\text { schools }\end{array}$ & $\begin{array}{l}\text { om state } \\
\text { colleges }\end{array}$ \\
\hline & $2001 / 02$ & $2002 / 03$ & $2003 / 04$ & $2004 / 05$ & $2005 / 06$ & $2006 / 07$ \\
\hline & $\%$ & $\%$ & $\%$ & $\%$ & $\%$ & $\%$ \\
\hline UK & 86.0 & 87.2 & 86.8 & 86.7 & 87.4 & 87.8 \\
\hline England & 85.2 & 86.4 & 86.1 & 85.9 & 86.9 & 87.2 \\
\hline Wales & 90.9 & 91.9 & 91.5 & 91.2 & 91.8 & 93.1 \\
\hline Scotland & 85.0 & 87.5 & 85.9 & 86.3 & 85.7 & 86.6 \\
\hline $\begin{array}{l}\text { Northern } \\
\text { Ireland }\end{array}$ & 99.7 & 99.9 & 99.8 & 99.7 & 99.8 & 99.6 \\
\hline
\end{tabular}

Source: HESA Performance Indicators in Higher Education in the UK

The HESA statistics also show that in the three intakes from 2002 to 2004, the proportion of young full-time first degree entrants to HEls in Wales from National Statistics Socio-economic Classification (NS-SEC) Classes $4-7^{1}$ was higher than that in England but very slightly lower in $2005 / 2006$. This change may have been indicative of the impact of the widening participation agenda in England, although in 2006/07 the proportion in Wales (30.1 per cent) was slightly higher than that in England (29.8 per cent).

In the 2006-2007 intake, Welsh HEls also had a higher proportion of young full-time first degree entrants from low participation neighbourhoods ${ }^{2}$ than was the case in the rest of

\footnotetext{
${ }^{1}$ These are groups below professional, managerial and intermediate occupations: 4 is small employers and own account workers; 5 is lower supervisory and technical occupations; 6 is semiroutine occupations; and 7 is routine occupations.

${ }^{2}$ Low participation neighbourhoods are defined as those for which the participation rate is less than two thirds of the UK average.
} 
the UK (10.2 per cent, compared to 9.6 per cent in England and an overall figure of 9.0 per cent for the UK). As with the case of Socio-economic Classification, this again highlights that, in comparison to English HEls, Welsh HEls have higher proportionate intakes of students from groups which tend to have higher levels of student withdrawal.

The difference was even greater for mature students (defined as being 21 or over at September $30^{\text {th }}$ of the academic year), with the proportion for $2006 / 07$ being 12.5 per cent in Wales, 11.4 per cent in England, and 10.6 per cent in the UK as a whole. This relative success, in Wales, of attracting students from low participation neighbourhoods, is important when considering the overall student retention statistics, as it indicates that Welsh HEls have been more successful in retaining students from groups which are more prone to withdrawing from HE. Moreover, it also highlights areas where further research may be required, in order to better understand student withdrawal in the Welsh context. For example, it will be seen that students from those groups which have traditionally had lower HE participation rates tend to have higher rates of withdrawal.

An important feature of the student body throughout the UK is the proportion studying part-time. In its study of part-time students in HE, Universities UK stated that over 40 per cent of UK HE students came into this category (UUK, 2006). In Wales, the proportion of undergraduate enrolments in 2006-07 who were studying part-time was 39 per cent (HEFCW, 2007). However, although the overall figure for Wales appears to be similar to that for the UK as a whole, HESA statistics for 2006/07 enrolments show a significant difference between Welsh HEls and those in the rest of the UK in the age distribution of part-time students. For the UK as a whole, only 7.6 per cent of those enrolling as part-time students were 'young entrants' (defined as those who are aged under 21 at 30th September of the academic year in which they are recorded as entering the institution), whereas in Wales the figure was 14.4 per cent.

This is indicative of Welsh HEls enrolling school-leavers on a part-time basis to a far greater extent than is true elsewhere in the UK. When placed in the context of the research finding that a full-time, first-degree student is three times more likely than a part-time student to continue their studies into a second year (National Audit Office, 2007: $p$ 8), it pinpoints an issue which warrants further investigation.

The HESA statistics also confirm the ongoing trend for HEls in Wales to have higher proportions of students in receipt of Disabled Students' Allowance (DSA) than other parts of the UK. For full-time first degree students, the proportion of such students in 2006/07 was 5.2 per cent in Wales and 4.4 per cent in England. In Wales, this represented a year by year increase, from 2.9 per cent in 2001/02. 


\section{Findings from Consultations}

As indicated earlier, consultations were carried out with representatives of DCELLS Higher Learning group, HEFCW, Higher Education Wales, National Union of Students Wales and two HEls. These discussions sought respondents' perceptions of the key points relating to student withdrawal and early course changing. As such, the intention was not to elicit hard factual data. Rather, it was to ensure that the subsequent literature review would concentrate on exploring findings, and statistical data, which were pertinent to the study. This section draws out the main points which arose during the consultations, without ascribing them to particular individuals.

\section{Student withdrawal and non-completion}

Some of those consulted suggested that variations between HEls in rates of student withdrawal may be attributable to the differing characteristics of the respective student bodies. In particular, the tendency for post-1992 universities to recruit higher proportions of part-time and 'widening access' students than their pre-1992 counterparts was highlighted, and offered as a factor in post-1992 universities also having higher rates of student withdrawal. As will be discussed in the next section, there are considerable variations between HEls in Wales in rates of non-continuation and noncompletion, which reflect differences in the characteristics of entrants.

Differences in the characteristics of students by subject area were also considered to be influential in determining rates of student withdrawal. It was noted that subjects such as nursing and creative writing tended to have higher proportions of mature students, who have a greater likelihood of withdrawal. However, the introduction of tuition fees has led to a reduction in the numbers of mature students recruited.

A range of factors which can contribute to student withdrawal emerged from the consultations, notably:

Finance - differences emerged between those consulted about the significance of finance. A student representative acknowledged that withdrawal often resulted from a combination of factors, but felt that finance was the most important factor. A particular issue in relation to this point is the need felt by many students to take jobs in order to finance their degree courses, with a consequent adverse effect on withdrawal and course changing. In contrast, while recognising it as potentially being a factor leading to the decision to withdraw, others agreed with recent studies (Quinn et al, 2005) which pointed to this being less important than other issues.

Socio-economic background - the relationship between socio-economic background and propensity to withdraw, with dropping out being more prevalent among students from lower socio-economic groups, was mentioned. Moreover, the system of tuition fees was felt to have created a disparity between the widening access agenda and the issue of student retention, with 'debt-averse working class people' not necessarily feeling that they fit in with $\mathrm{HE}$. Also, an $\mathrm{HEI}$ representative asserted that students from lower 
income families tended to require student support to a greater extent than those from families with higher incomes.

Lack of tradition of $\mathrm{HE}$ - for those students from families with no prior tradition of HE, difficulties may be encountered in coping with the HE experience. In particular, it was felt that they could feel intimidated if studying traditional, professional subjects such as law or medicine, which tended to recruit students with family backgrounds in those subjects.

Realistic expectations - problems can arise from the 'reality' of the HE experience differing from students' expectations, particularly if they have been led to believe that it will be relatively easy. In such circumstances, appropriate support is required - from peers, members of staff etc and through learning resources.

Academic demands - the academic demands of $\mathrm{HE}$, and the step change in thinking required of students to meet these demands was put forward as a reason for some students' withdrawal. The requirement for the necessary academic ability was essential in order for students to be able to 'stay the distance'.

Students offered places through clearing - a disparity between those who had gained their place through clearing and those who had received their offer of a place much earlier in the year, with the former being more likely to drop out, was mentioned. It was suggested that this was often due to their enrolling at HEls in locations which they had not previously visited and/or enrolling on courses which were not their first choice.

Inadequate facilities - it was stated that some HEI vice-chancellors partly attributed student withdrawal to students' perceptions that the 'shoddy facilities' offered are not up to the anticipated standard. This encompassed student accommodation and the infrastructure, particularly in relation to IT facilities, with which students were confronted within their HEl. As a result, students sometimes felt that they were not valued by the HEl.

Students feeling valued - allied to the above point, the need for HEls to make students feel valued, so that they feel part of something they want to be part of, was emphasised.

A consultee for this review contended that the time at which students were most vulnerable to deciding to drop out was after around six weeks - when they had to hand in their first assignment. This was supported by attendees at the 'Staying the course: The retention of students in higher education' conference, run jointly by The Higher Education Academy, the National Audit Office and HEFCE, on April $1^{\text {st }} 2008$.

\section{Early course changing}

Unlike student drop-out, early course changing was not considered to be an issue of concern among respondents in the consultation phase. This was partly attributed to the development of more appropriate student support systems. In particular, the shift from a system whereby anyone changing course placed their funding at risk for the whole of the first year, to one where student funding is based on 3 or 4 years plus one year, means 
that students are able to "have a second bite of the cherry" without losing funding. This has made it easier for students to move around without risk of penalty.

The system of credit and an emphasis on modularisation were also factors which helped to render early course changing relatively unproblematic. Students in post-1992 universities were felt to be more mobile, with HEls such as the University of Glamorgan and NEWI adapting their processes to accommodate these shifts. Pre-1992 universities were considered to be slower in introducing system changes.

\section{Key issues}

As well as identifying factors which contribute to student withdrawal, there emerged from the consultations a range of issues which were regarded as being highly pertinent to the discussion.

\section{Cultural dynamic}

The importance of social networks and contacts for enabling new entrants to cope with the HE experience was flagged up. This was related to the notion of a 'cultural dynamic', whereby entrants to HE from working class backgrounds and/or disadvantaged areas, and who represent the first generation of their family to aspire to $\mathrm{HE}$ may be less prepared and less able to cope with both the learning and social aspects of life at an $\mathrm{HEI}$ than those from family backgrounds where there is prior knowledge and experience of HE. This situation may result in undue pressure on the former, who may have unrealistic expectations of what awaits them.

\section{The role of the personal tutor}

The importance of the role of the personal tutor, firstly in identifying difficulties or disenchantment on the part of the student, and secondly in responding to those difficulties, was emphasised. Personal tutors, who are part of educational provision, were seen as being in the front line and in a position where, if appropriate, they could refer the student to the student support team. Initially, it was felt that, rather than students who were considering withdrawing resorting to the bureaucratic process involved, they should be encouraged to discuss the matter with their personal tutor or a member of the student support team. An HEI representative stressed that the personal tutor or student support team should not work on the principle of advising not to withdraw. Rather, they should attempt to put in place mechanisms to address the specific issues which had led the student to contemplate withdrawal.

\section{Widening access agenda}

It was felt by representatives of HEls that the assumption that students who had been attracted to $\mathrm{HE}$ as a result of the widening access agenda were at greater risk of withdrawal and/or non-progression should be challenged. One respondent sought to differentiate between what was termed 'responsible' and 'irresponsible' widening access. The point being made here was to call into question the recruitment process which 
resulted in more than one in five of entrants withdrawing in the first year, with, for many, the detrimental effect this had on their self-confidence and future career trajectories.

\section{Funding of HE}

The 'funding gap' between Wales and England was mentioned as a constraint on Welsh HEls, which, it was felt, were less well resourced than their English counterparts. This had implications for their competitiveness and the resources available to them. The importance of the need for the Welsh Assembly Government to recognise that the allocation of funding to HE should be regarded as an investment was stated. Crucially, one respondent highlighted what they considered to be a significant gap between the funding model in operation in Wales and what the sector was attempting to do to address student retention.

An HEI representative stated that the numbers of mature students enrolling had declined as a result of the introduction of tuition fees.

\section{Student finance}

At present, the level of fee remission available to Welsh domiciled students enrolling at HEls in Wales makes this an attractive option. However, there is widespread scepticism about whether such a policy is sustainable, economically, in the longer term.

The poor take-up of bursaries and falling levels of applications to the Financial Contingency Fund were cited as indications of finance not being as pressing an issue for students as is often claimed.

The lack of robust data about the impact of tuition fees on student participation and withdrawal was remarked upon, with the caveat that it was too early to assess the extent of any impact. However, the increase in Welsh students attending Welsh HEls was considered to be partly attributable to the fee remission available to these students, which is non-means tested.

\section{Foundation degrees}

An $\mathrm{HEI}$ representative considered the introduction of Foundation degrees to be an important issue in relation to student retention, for both full-time and part-time students. In particular, they eased the transition to HE by enabling students to become accustomed to the academic demands they would encounter. This accorded with the description of them as being "seen by many HEls/FEls and employment organisations as an important 'stepping stone' qualification, particularly suited to part-time learners in work" (SQW, 2007). The SQW report (2007) noted that earlier studies of Foundation degrees (York Consulting, 2004) had identified retention "as a problem in some of the early programmes, mainly because some students were missing the underpinning knowledge necessary to complete the qualifications. Balancing work and study can cause students to struggle, leading to early drop-outs" (SQW, 2007: p 15). However, as far as Foundation degrees in Wales were concerned, it was concluded that more effective recruitment practices should have alleviated the problem. 


\section{Students in Years 2 and 3}

It was felt that a lot was known about students' first year experience of $\mathrm{HE}$ and the issue of student withdrawal, as exemplified by the fact that both HEFCW and HEW have recently initiated reviews of the literature and associated evidence. However, relatively little has been done to assess students in Years 2 and 3, and the factors which may lead them to decide to withdraw. It was suggested by one respondent that the issues may be different from those which affect first year students. For many, their lifestyle may have changed, having moved out of student accommodation, their workload could be increasing and they may be becoming anxious about their future careers. Furthermore, for some, the demands of part-time employment, which they may need to undertake for financial reasons, may be further detracting from their ability to perform sufficiently well in their studies.

\section{Policy initiatives}

During the consultations, the role of accreditation was considered to be important in Wales, as provision was funded on learning units and therefore afforded flexibility for students to move between institutions or to part-time study. Therefore, credit can be viewed as a facilitator of movement within the system which enables students to change course or institution to something which they find more suitable, thereby reducing the likelihood of withdrawal.

The fact that HEls in Wales receive a premium for the numbers of students enrolled who are in receipt of Disabled Students' Allowance (DSA), helps to explain the higher proportion of those students, in comparison to England and Scotland.

It was stated by one respondent that the refocusing of the Reaching Higher Strategy, which is due to take place in 2010 , is likely to place greater emphasis on student retention.

A respondent flagged up the key role of the Reaching Wider Partnerships, which are led by HEls and involve feeder schools, in making potential entrants to HE better informed about what they will face. This sometimes entails organising university taster days and summer camps. In conjunction with HEl staff, the Partnerships are able to provide valuable information, advice and guidance which is targeted at young people who are about to leave school. Given the perception that a lack of understanding of what would be required of them in $\mathrm{HE}$ can be a contributory factor to a decision to withdraw, this is also a mechanism for enhancing student retention.

Another interesting point which was raised was the possible impact of the Leitch Report and its emphasis on the upskilling of all adults. For this to happen, greater emphasis may be placed on ensuring that those engaged in pursuing higher level qualifications do not withdraw before this has been achieved. Therefore, there could be increased interest in understanding the phenomenon of student withdrawal in the coming years. 


\section{Institutional responses}

As far as Wales is concerned, a contributor commented on the lack of flexibility within HEls, with special reference to the pre-1992 universities. This was regarded as a constraint on the introduction of measures to address students' requirements for support. Another respondent considered that the Russell Group universities were able to devote more resources to student support systems, yet it was harder for those in the groups most at risk of withdrawal to gain entry.

Contrasting views emerged about the relative merits of pre-1992 and post-1992 HEls, in terms of the support provided for students. One of those interviewed felt that post-1992 universities tended to have higher drop-out rates, because they had more part-time and 'widening access' students from families with no history of going to HE in their cohorts. As a consequence, they also tended to place greater emphasis on pastoral care for students.

This view was challenged by a respondent who contended that there was a 'myth' among HEls that just because some were regarded as being small and friendly, they therefore tended to be more supportive of their students. A counter argument was that larger HEls tended to be better resourced and could offer higher levels of formal support.

Among the measures which were mentioned as having the potential to alleviate some of the problems associated with student withdrawal was the use of pre-entry taster courses or summer schools which enabled prospective students to gain some first hand experience of $\mathrm{HE}$, and therefore of what they may expect to find after enrolling. However, the respondent also acknowledged the shortcomings of this approach, notably the fact that it placed applicants in a situation which was certainly not real. The main purpose of these activities was perceived to be marketing, rather than an attempt to reduce the likelihood of student withdrawal.

A better way of introducing applicants to what life in HE was all about was the idea of them taking modules, possibly lasting a whole term. The emphasis would be on selfdirected learning. It was reported that Cardiff University was already offering this kind of pre-entry provision.

As indicated earlier, personal tutors were regarded as being in the front line of support for students, followed by student support services. It was envisaged in one HEI that the student support services were becoming seen as part of educational provision.

Furthermore, the approach being taken placed emphasis on not necessarily advising students against dropping out. Rather, the intention was to put in place mechanisms which addressed the issues which may lead to students considering dropping out. By placing the individual's, rather than the institution's needs, at the forefront, the student services unit was essentially adopting the role of 'honest broker' which has traditionally been espoused by career advisers. This provision of impartial advice and guidance highlights the importance of the role of HEls' careers advisory services in addressing students' needs (Maguire, 2005). 
The introduction of peer mentoring schemes, involving second and third year students, and more rigorous and regular monitoring of data relating to student withdrawal were also mentioned as ways of addressing retention issues.

\section{Policy development}

In terms of future policy developments, the following were mentioned as key areas by those consulted, as far as student withdrawal was concerned:

- Given the imminent revision of the funding methodology for HE in Wales, the idea of relating funding to completion rates, rather than to the numbers starting courses, was put forward;

- A related idea was for the funding of HEls to be based on the 'distance travelled' over time by students, incorporating achievement as well as completion. It was suggested that investment in HEls on this basis would disproportionately affect student retention;

- Greater collaboration, rather than competition, between HEls and FEls should be further encouraged;

- The need for more training of personal tutors, in order to be able to offer a greater level of support and pastoral care, was proposed;

- A greater emphasis on the provision of information and advice at the pre-entry stage, through working with schools and colleges of further education, was thought to be advisable in order to prepare entrants for the HE experience.

\section{Gaps in knowledge}

Although HEls are to a great extent autonomous and are often resistant to external intervention, policy makers felt that any research on the issue of student withdrawal which was undertaken as part of the CRP 2007-2010 would be helpful for the process of refreshing the Reaching Higher initiative.

In particular, it was stated that it would be interesting to know more about the extent to which finance contributes to withdrawal, especially in relation to the issue of the fee cap.

Although some work has started on gaining a deeper understanding of the issues which affect the entry and continuation of black and ethnic minority (BME) students in HE, further investigation of this aspect of access to HE would also be welcomed.

Another issue which was raised concerned the delivery of HE courses by Further Education institutions. There is some, at least anecdotal, evidence that retention rates vary between those courses which are delivered within $\mathrm{HE}$ and those which are delivered by Colleges of Further Education, with rates in the latter being higher.

It was also stated that it would be useful to identify good practice among HEls in the way in which they were addressing the issue of student withdrawal and to get to know more about what activities and mechanisms were particularly effective in supporting retention. 
The relationship between particular HEl approaches and practices which effected improved student retention and the characteristics of the students who were targeted by these practices were thought to be worthy of consideration.

The overriding focus of the student retention debate being on full-time students, together with a dearth of literature about the retention of part-time students, were reasons given for undertaking work which looked at the latter.

Also, while there is a plethora of research and comment about withdrawal among first year students, it was felt that more needed to be known about those who dropped out in Years 2 and 3. It was hypothecated that their lifestyles differed to some extent from those of first year students, and they often experienced increasing workloads and apprehension about imminent career decisions.

Another possible area of research which was mentioned was a comparison between the experiences of home-based and campus-based students.

While there is much literature which considers the need for and role of student support, careers advice and counselling support, a more challenging area for study would be to assess how students were able to cope with the 'academic endeavour' required to successfully navigate a course through $\mathrm{HE}$.

Following on from the notion identified earlier that the assumption that 'widening access' students were equated with a greater propensity to withdraw from HE should be challenged, studies which set out to do this would be welcomed by those who were consulted.

At a practical level, there was a call for a study of the impact of the student bursary scheme on recruitment and retention, and, in particular the extent to which it reduced the likelihood of withdrawal.

Underpinning much of the discussion of student retention, it was felt that HEls should be more assiduous and probing when compiling data about withdrawal and the reasons given for it. This would provide a sounder foundation for assertions about the characteristics of those who withdrew, and the factors which impinged on that decision. 


\section{Student Withdrawal}

This section considers the literature on student withdrawal. The aspects of the topic which are discussed are:

- Completion and continuation rates;

- Characteristics of non-continuing students;

- Reasons for withdrawal;

- Factors affecting students' decisions to withdraw; and

- When withdrawal occurs

\section{Completion and continuation rates}

A recent report (National Audit Office, 2007) on Higher Education in England distinguishes between two measures of student retention:

1. the 'completion rate', which refers to the proportion of starters in a year who continue their studies until obtaining a qualification; and

2. the 'continuation rate', which is the proportion of students entering an HEI who are enrolled in the following year.

By analysing HESA statistics, the report concluded that 91.6 per cent of first degree students enrolling in 2004-05 continued into their second year, while 78.1 per cent were projected to qualify with a first degree. It will be important to be clear about the distinction between these measures, when assessing the literature and drawing conclusions for the work to be carried out as part of the CRP 2007-2010. While the proportions continuing into Year 2 are based on actual numbers, the projections of attainment in Year 3 are predictive figures based on "current progression patterns at their institution" (HESA website). What is significant about these figures, however, is that, while considerable attention is paid in the literature to the 8.4 per cent of those not continuing into Year 2, there is relatively little about the 21.9 per cent who do not progress to attaining a first degree. It could be argued that while withdrawal within the first year could, as will be seen, be for a variety of reasons and in some cases a positive move, the significantly higher proportions who do not progress sufficiently to achieve a degree constitutes a more fundamentally worrying problem, in individual, social and economic terms.

A key point made by the National Audit Office report is that the United Kingdom has higher rates of graduation than the majority of OECD countries, and that the figures for the 2004-05 intake for the UK represented a slight improvement on the comparable figures for 1999-2000 (National Audit Office, 2007). 
Commenting on the NAO report, David Eastwood, Chief Executive of the Higher Education Funding Council for England (HEFCE), suggests that, rather than having a high withdrawal rate, a comparison of student participation rates over time points to there having been only a slight increase in non-completion rates at a time when participation rates more than doubled (Eastwood, 2008). His conclusion was that "the transition to mass higher education was achieved without the predicted catastrophic increase in drop-out rates".

At the time of the launch of Reaching Higher in 2002, Welsh HEls had a lower noncontinuation figure, in comparison to the UK as a whole. The Reaching Higher document stated that " $8 \%$ of all full time first degree entrants in Wales in 1998-99 did not continue in HE beyond the year of entry, compared to $10 \%$ in the UK as a whole", and that " $9 \%$ of young full time students from low participation neighbourhoods did not continue in HE after their first year, compared to $6 \%$ from other neighbourhoods. These figures are lower than the UK average" (Welsh Assembly Government, 2002, p 9).

As far as non-completion is concerned, HEFCW's Welsh Higher Education Statistics 2004/05, drawing on HESA data which provides a comparison across the four home countries, asserted that "non-completion rates of full-time students starting first degrees in Wales were slightly higher than for the UK as a whole". The estimate for Wales was 15.4 per cent of students neither obtaining an award nor transferring to another HEI, compared with 14.9 per cent for the UK as a whole (HEFCW, 2008a).

Since that time, there has been a change in the comparative rates of Welsh and English HEls. The latest HESA statistics relating to continuation and completion ${ }^{3}$ show that, in both cases, those for Welsh HEls are higher than the figures for England and for the UK as a whole. Of young full-time first degree entrants in 2005/06, 7.8 per cent of those in Wales did not continue in HE after the first year. This compares to 6.7 per cent in England and 7.1 per cent for the UK. For mature full-time first degree entrants, the comparable figures were 15.2 per cent in Wales, 14.2 per cent in England and 14.3 per cent in the UK (HESA website).

However, the downward trend in Wales was greater than elsewhere in the UK. For young full-time first degree entrants, the figure represented a 0.4 percentage point fall from the previous year, whereas in England and the UK as a whole, there had only been a 0.1 percentage point reduction. For mature full-time first degree entrants, the figure for the UK for 2005/06 was 0.1 percentage points lower than for the previous year, while for England the proportion had risen by 0.2 percentage points. In Wales, there had been a 1.5 percentage points reduction. Thus, in the case of both young and mature full-time first degree entrants, the downward trend for non-continuation levels was considerably greater in Wales than elsewhere in the UK.

Within the overall figures, there are considerable differences in the rates of withdrawal between the various HEls in Wales (Table 6). The statistics for first degree courses

\footnotetext{
${ }^{3}$ The data referred to here is derived from the HESA website.
} 
2004-05 showed that the projected withdrawal rate for the University of Glamorgan was 29.9 per cent, while that for the University of Wales, Bangor and the University of Wales, Lampeter were 22.5 per cent and 21.1 per cent respectively. At the other end of the scale, the rate for University of Wales, Swansea was only 11.1 per cent, and that for Cardiff University, which, with over 5,000 starters is by far the largest of the HEls in Wales, was even lower at 9.8 per cent.

Table 2: Projected graduation and dropout rates for first degree courses 2004-05: Wales

\begin{tabular}{|c|c|c|c|c|c|}
\hline Institution & $\begin{array}{r}\text { Number of } \\
\text { starters }\end{array}$ & $\begin{array}{r}\text { Degree: } \\
\text { Projected } \\
(\%)\end{array}$ & $\begin{array}{r}\text { Degree: } \\
\text { Benchmark } \\
(\%)\end{array}$ & $\begin{array}{r}\text { Dropout } \\
\text { rate: } \\
\text { Projected } \\
(\%)\end{array}$ & $\begin{array}{r}\text { Dropout } \\
\text { rate: } \\
\text { Benchmark } \\
(\%)\end{array}$ \\
\hline $\begin{array}{l}\text { University of Wales, } \\
\text { Aberystwyth }\end{array}$ & 1970 & 83.5 & 80.4 & 9.6 & 12.0 \\
\hline $\begin{array}{l}\text { University of Wales, } \\
\text { Bangor }\end{array}$ & 1975 & 70.2 & 76.6 & 22.5 & 14.7 \\
\hline Cardiff University & 5485 & 85.8 & 84.0 & 9.8 & 9.1 \\
\hline $\begin{array}{l}\text { University of Wales } \\
\text { Institute, Cardiff }\end{array}$ & 1970 & 79.2 & 76.2 & 14.4 & 15.5 \\
\hline $\begin{array}{l}\text { University of } \\
\text { Glamorgan }\end{array}$ & 2945 & 62.9 & 63.2 & 29.9 & 25.2 \\
\hline $\begin{array}{l}\text { The University of } \\
\text { Wales, Lampeter }\end{array}$ & 270 & 67.2 & 70.7 & 21.1 & 20.2 \\
\hline $\begin{array}{l}\text { The University of } \\
\text { Wales, Newport }\end{array}$ & 940 & 69.8 & 72.5 & 23.2 & 19.1 \\
\hline $\begin{array}{l}\text { The North-East Wales } \\
\text { Institute of Higher } \\
\text { Education }\end{array}$ & 810 & 63.9 & 69.5 & 25.0 & 20.8 \\
\hline $\begin{array}{l}\text { Royal Welsh College of } \\
\text { Music and Drama }\end{array}$ & 145 & 86.7 & 79.9 & 4.1 & 12.4 \\
\hline $\begin{array}{l}\text { Swansea Institute of } \\
\text { Higher Education }\end{array}$ & 855 & 71.1 & 76.3 & 24.1 & 16.1 \\
\hline University of Wales, & 2725 & 82.0 & 78.3 & 11.0 & 13.3 \\
\hline
\end{tabular}


Swansea

Trinity College,

Carmarthen

460

81.0

76.1

15.0

16.4

Total Wales

20555

77.1

16.5

Source: HESA

However, citing these overall figures for each institution can be misleading, as they do not take account of the differences between institutions in terms of the composition of the student body. It may be more appropriate to look at the benchmark figures which are assigned to each institution. These are derived from a consideration of the subject mix, the qualifications on entry, and age on entry of the student population, thus acknowledging that student withdrawal is more likely to occur among students with lower qualifications on entry and/or those studying particular subjects. ${ }^{4}$ As the table indicates, the disparities between these benchmark figures and the actual figures are significantly less pronounced. For example, although Cardiff University has a low projected drop-out rate of 9.8 per cent, this represents a performance which is worse than the benchmark of 9.1 per cent. On the other hand, the University of Wales Institute, Cardiff has a higher projected non-completion rate of 14.4 per cent, yet this is well within the benchmark figure of 15.5 per cent. Thus, entrants to Cardiff University tend to have higher levels of qualifications on entry and tend to be studying subjects which have low rates of student withdrawal, than is the case at the University of Wales Institute, Cardiff.

The explanation for this is that levels of prior attainment are taken into account in the setting of the HESA benchmarks, and this is why benchmarks tend to be considerably higher at post-1992 universities than at pre-1992 HEls.

An important piece of research focusing on non-continuation is that undertaken by Helen James, Director of Higher Education Strategy and Further Education Development at North East Wales Institute of Higher Education (NEWI). This has involved a time series analysis of performance among HEls in Wales from 2001/02 to 2003/04 (James, 2007). This work found that, while there had been a gradual increase in the non-continuation in HE of full-time first degree young entrants over the period, there had been reductions at the University of Wales, Bangor and at the University of Aberystwyth.

Marked differences were noted between, on the one hand, post-1992 universities and Institutes of Higher Education, where the levels of non-continuation ranged from 12 per cent to 18 per cent, and traditional pre-1992 universities, where the levels ranged from 4 per cent to 8 per cent.

\footnotetext{
${ }^{4}$ It should be noted that the methodology employed to generate the benchmarks has been questioned (James, 2007), on the grounds that it takes insufficient account of the combination or accumulation of characteristics associated with non-traditional students.
} 
As far as full-time first degree entrants from low participation neighbourhoods were concerned, the overall trend was for non-continuation rates to increase, apart from at NEWI and Swansea Institute for Higher Education (SIHE), which both have good reputations for their widening access policies, and at the University of Wales, Swansea. On the basis of this analysis, James concludes that when the impact of the widening access agenda, which has been particularly successful in Wales, is taken into account, "Wales outperforms the UK average across many of the indicators, some by as much as $5 \% "$

\section{Characteristics of non-continuing students}

In terms of what are considered to be characteristics which are commonly associated with groups or individuals who are over-represented among those who withdraw from higher education, a range has been identified within the literature. These are discussed under the following sub-headings:

- Age

- Gender

- Ethnicity

- Socio-economic classification

- Prior educational attainment

- Full-time/part-time study

- Disability

- Subject area of study

- HEl attended

Age

Age has been identified as a differentiating factor for continuation and completion. The report on Improving Student Achievement in English Higher Education (National Audit Office, 2002) highlighted the fact that older students were more likely to fail to complete their degrees. More recently, a report focusing on continuation rather than completion (National Audit Office, 2007) has pointed up a significant difference between students aged 21 and over and those under 21 in the likelihood of continuing on to a second year. HESA statistics for 2005/06 show that the non-continuation rate of full-time first degree students under the age of 21 on $30^{\text {th }}$ September of the year in which they entered HE was 7.8 per cent, with that for full-time first degree students aged over 21 being almost twice that figure, at 15.2 per cent.

Charlton et al (2006) suggest that these differences are partly attributable to the contrasting characteristics of the two sets of students, with those aged over 21 being more likely to "be married, have children and be based at home", thereby leaving them less time for study. This accords with Yorke and Longden's (2008) finding that those without prior experience of $\mathrm{HE}$ tended to cite the wrong choice of field of study as a reason for withdrawing, while those with experience mentioned financial problems and the needs of dependants. Alternatively, it has been argued that older students are more highly committed to their HE studies due to their interest in the subject and/or the 
enhanced job prospects which will ensue (Ozga and Sukhnandan, 1998; Tinto, 1993). Ozga and Sukhnandan suggest that this level of commitment helps them to be better prepared for the HE experience. As Charlton et al (2006) explain, support for both these perspectives can be gained from interpretations of the findings of Davies and Elias' study (Davies and Elias, 2003), which identified 'wrong choice of course' as the main reason from withdrawal by those aged under 21 , and 'financial problems' as the main reason for those aged over 21. This latter point is supported by Ozga and Sukhnandan's finding that the need to earn more money, along with a need to be at home more, were the principal factors in older students' decisions to withdraw.

Notwithstanding these contrasting interpretations of data to explain how the age of the student may impact on the decision to withdraw, it remains clear that students aged under 21 tend to continue into a second year to a far greater degree than do older students.

Yorke and Longden (2008), in their recent study of over 7,000 first year students in the UK, found that students aged under 21 were more likely than older students to feel that they had made the wrong choice of course or institution, lacked commitment, or were not progressing academically. In terms of the reasons for withdrawal, it was found that;

- young students choose programmes less well than older students

- young students are more likely than older students to be unhappy with various aspects of the geographical environment in which they live and/or study

- older students tend to be more critical than younger students of their experience in higher education

- older students have greater problems with finance, with the demands of part-time study, and with the needs of dependants

(Yorke and Longden, 2008)

\section{Gender}

The last twenty years have seen a dramatic change in the rates of participation in HE by gender in the UK. Prior to 1992, women had been under-represented. By 2005/06, however, "Higher Education Initial Participation Rate figures for 17-30 year olds showed a 7.2 percentage participation gap in favour of women - a gap which appears to continue to widen" (Broecke and Hamed, 2008). In Wales, HEFCW figures for enrolments in 2004/05 show that 57 per cent of those enrolling were female.

Despite these substantially higher rates of participation in HE for females, noncontinuation rates are considerably higher among young men. Moreover, this pattern appears to be longstanding (Charlton et al, 2006). Yorke (1999) observed, on the basis of UK data from the 1970s to the 1990s, as well as American data for the 1990s, that there was consistently a five percentage point difference between the drop-out rates for the two groups, with males being considerably more likely to withdraw.

Using a regression model to calculate odds ratios, which "compare the probabilities of continuation for two groups of students whilst other characteristics remain constant" 
(National Audit Office, 2007), the NAO report found that, for the 2004/05 intake to HEls in the UK, males were significantly less likely than females to continue (odds ratio of 0.77 ). This analysis provides powerful evidence across a range of factors which may or may not be correlated with non-continuation. It is applied to data from HESA's Individual Student Record, which, in the case of the 2004/05 intake, consisted of 299,000 full-time students and 229,000 part-time students.

Quinn et al, recognising this gender difference in propensity to withdraw from HE, and persuaded that "it is young working class provincial men who are causing policy-makers most concern" (Quinn et al, 2005), undertook a study which focused on this group. Forty of the 67 working class students under 25 years of age who were interviewed in-depth for their study of working class drop-out from university were white men. It was found that gender was an important factor in differentiating those who made particular subject choices, with males tending to opt for engineering and computer related courses and females preferring business related courses. This, in itself, could contribute to differences in the likelihood of withdrawing from HE, for, as the National Audit Office report indicated, the odds ratio for the chances of continuing to a second year for those "studying a strategically important science, technology, engineering or mathematical subject", in comparison to those studying other subjects, was 0.84 . This identifies students of those subjects to be more likely to withdraw before the second year.

Yorke and Longden (2008) found that males tended to cite financial problems as the reason for withdrawal to a greater extent.

\section{Ethnicity}

A study of official statistics covering English HEls concluded that "minority ethnic students are more likely to leave degree courses early than White students, and Black more likely than Asians. Allowing for the main factors that cause early leaving (eg entry qualification and entry route) and also controlling for other differences (like subject, gender, age), the apparent difference reduces significantly" (Connor et al, 2004). This is an important finding, for it suggests that, although minority ethnic students are perceived to have higher rates of withdrawal, ethnicity itself may be less of an issue than other factors, such as age and qualification attainment.

The National Audit Office report (2007) offers some support to Connor's conclusion that ethnicity is not a significant factors in explaining or predicting withdrawal from HE. For full-time entrants to courses in 2004/05, in comparison to their White counterparts, 'other white background', Black, Pakistani and Bangladeshi, Indian and Chinese, and 'other Asian background' students all had odds ratios of more than 1.00 in their chances of continuing to a second year. Thus, they were less likely than White students to withdraw. Mixed race students had the same probability as White students to continue. Only 'other ethnic background' and 'ethnicity unknown' students were more found to be more likely to withdraw. Given these differences between minority ethnic groups in the propensity to withdraw from $\mathrm{HE}$, it may be appropriate to focus any study of ethnic minority withdrawal which is considered for the CRP 2007-2010, on specific groups. 
As far as reasons for withdrawal are concerned, a recent study found that non-white students were much more prone than white students to indicate that financial problems were the cause of drop-out (Yorke and Longden, 2008). On the basis of his findings from two student surveys, one conducted in the mid-1990s and one conducted in 2005-07, Yorke (2008) states that 'other than white' students are more likely to mention the following factors as contributing to the decision to withdraw:

- aspects of teaching quality

- contact with academic staff

- programme organisation

- aspects of institutional resourcing

In a study of minority ethnic trainees who withdrew from initial teacher training courses, Basit et al (2006) concluded that 'personal' and 'family' reasons were most frequently cited as the causes of withdrawal.

Lower socio-economic groups

The Staying the course: The retention of students in higher education report (National Audit Office, 2007) points to certain factors being significant when seeking to compare completion and continuation rates over time or across institutions. Crucially, it posits that the widening participation agenda has resulted in increasing numbers of students from working class backgrounds entering $\mathrm{HE}$, and that these have traditionally had higher rates of withdrawal.

The regression analysis undertaken for the National Audit Office report (2007) identified that, for full-time students who entered in the 2004/05 academic year, those from socioeconomic classification 4-7 backgrounds were less likely to continue into a second year than those from socio-economic classification 1-3 backgrounds ${ }^{5}$. However, as far as part-time students were concerned, the opposite was true, with those from socioeconomic classification 4-7 backgrounds being significantly more likely to continue. This is a particularly interesting finding as it runs counter to conventional wisdom, which would suggest that these students from lower socio-economic groups would be more prone to experiencing financial constraints and less likely to be able to call on family and friends with a tradition of participation in HE to offer support

The argument that students from lower socio-economic groups are more likely than their counterparts from higher socio-economic groups to withdraw from HE has been made elsewhere. Quinn et al (2005) contended that "recent statistical analysis of the probability of withdrawal for UK university students indicated that non-completion was more probable for students from low-ranked, occupationally defined social classes (Smith and Naylor, 2001) than for other classes" (p 3). Assuming a correlation between social class and level of income, this is also supported by Forsyth and Furlong's (2003)

\footnotetext{
${ }^{5}$ See footnote to $\mathrm{p} 15$ for classifications
} 
finding, from a study in Scotland, that non-continuation was more common among poorer students.

Another relevant recent finding is that students from managerial and professional backgrounds are less likely to experience financial difficulties than those from other socioeconomic groups (Yorke and Longden, 2008). The same study suggested that students from non-managerial or professional back grounds tended to cite "workloads, class size and stress related to the demands of the programme" as reasons for withdrawal.

\section{Lower prior attainment}

It is recognised in the literature that a relationship exists between the level of prior qualification attainment and the likelihood of continuing into a second year in HE. Referring to Yorke's analysis of undergraduate non-completion in the 1990s (Yorke, 1999), Charlton et al (2006) state that "lower A-level grades are associated with a greater likelihood of withdrawal and poorer degree classification". More recent evidence supports this case, with a key finding of the NAO report being that "a full-time student with three $A$ levels at grade $A$ is much more likely to continue than a similar student with two A levels at grade D (odds ratio of 2.2)" (National Audit Office, 2007: p 8). For fulltime students, pre-entry qualifications were stated to be "the biggest influence on likelihood of continuation".

As will be discussed later in this section, the explanation offered for this relationship between qualification attainment prior to entering $\mathrm{HE}$ and subsequent propensity to withdraw is the greater difficulty encountered by those with lower attainment in coping with the academic demands of HE. Davies and Elias (2003) suggested that this was the case, while acknowledging that an inadequate response rate to their survey from those with low levels of pre-entry qualifications prevented them from being definitive about this.

These findings confirm those of Yorke (1999), and are in line with Davies and Elias' (2003) data which showed that the inability to keep up academically was a major factor in explaining the decision to withdraw. However, Charlton et al's study (2006) sought to test out this assumption through comparing the average GCSE performance of continuing and withdrawing students. They concluded that, while continuing students tended to have performed better at GCSE than those who dropped out, the effect of this variable was less important than the effect of motivation, and independent study expectations. Their statement that "this supports McGivney's (1996) conclusion that motivation is of greater importance than educational qualifications in determining progression." ( $p 44$ ) suggests that lower prior attainment is less important than other factors.

\section{Part-time students}

The NAO report notes that, of the 50,000 part-time first degree students who started in 2004-05, only 76.9 per cent continued into the second year. This compared to 91.6 per cent of full-time first degree students, and meant that the odds ratio between the two 
was 3.3. Interestingly, however, it was found that "a part-time student registered with a higher education institution but taught in a further education college is more likely to continue than a similar student in a higher education institution (odds ratio of 1.6)". The opposite is true for full-time students. The chances of continuation for part-time students was also found to be enhanced where they had initially undertaken a Foundation degree and gained part exemption from the full degree course.

The conclusion reached was that "the factor most affecting a student's chance of continuing is whether they are studying full-time or part-time, with full-time students being much more likely to continue if other factors are held constant" (National Audit Office, 2007: p 20).

\section{Students with disabilities}

A key aspect in relation to continuation among disabled students is whether they are registered for the Disabled Students Allowance (DSA). Those students who are registered have a greater likelihood of continuation than all other students (National Audit Office, 2007). The HEFCW statistics for enrolments in 2004/05 show that, for fulltime students, just over half (54 per cent) who had some disability were known to be in receipt of DSA. For part-time students, the proportion was much lower, at 15.6 per cent (HEFCW statistics). The success of those who register and continue is attributed, in part, to the likelihood that they have a high level of perseverance, as evidenced by their preparedness to go through the complex application process.

In terms of the reasons given for withdrawal, Yorke and Longden (2008) found that students with disabilities were more likely to cite personal health, lack of support from staff and students, and large class sizes.

\section{Students of certain subject areas}

The extent to which the subject studied can be a predictor of propensity to continue into a second year, or to complete their course, has been acknowledged in the literature (Pugh et al, 2005). According to the NAO report, "students on particular courses are more likely to stay on the course than others" ( $p 20)$. In particular, it was noted that Medicine and Dentistry (98 per cent continuation rate) had considerably higher continuation rates than most other subjects; for example, Combined Subjects only had a continuation rate of 83 per cent. The lowest rates were found in Combined subject degrees and Mathematical and Computer Sciences. Mathematics and Computing were also identified by Pugh et al (2005) as subjects whose students were less likely to complete.

This may be regarded as predictable, for, as Pugh et al (2005) state: "the age, gender, and social, cultural and racial profiles of students vary across subjects" ( $p 26)$. Thus, it is the characteristics of the students taking particular subjects which is the determining factor.

Those attending post-1992 HEls 
Quinn et al (2005) point to the HESA statistics which indicate that rates of completion are lower in post-1992 universities (HESA, 2004). As far as withdrawal (or noncontinuation) is concerned, the NAO (National Audit Office, 2007) report confirmed these findings. HEls were placed in four categories:

- The Russell Group

- Pre-1992 universities (excluding the Russell Group)

- Small and specialist institutions

- Post-1992 universities

Within English HEls, variations were found between the longer-established universities, such as those which form the Russell Group, and the post-1992 institutions. The conclusion drawn was that "on average, The Russell Group universities have the highest continuation rates for full-time students and the universities created after 1992 have the lowest rates overall. These broad variations largely reflect the types of students they enrol and their level of pre-entry qualifications" (National Audit Office, 2007, p 18). The disparities which were identified earlier between HEls in Wales in their non-continuation rates suggest that the same is true in Wales. This, again, can be partly attributed to differences in the characteristics of the respective student bodies, with post-1992 HEls tending to enrol students who are more likely to have lower levels of prior qualifications and come from backgrounds and communities which have not traditionally produced $\mathrm{HE}$ entrants. Thus, as with the previous discussion of subjects studied, the characteristics of the students attending the different types of HEls are key in differentiating rates of non-continuation and non-completion.

Focusing on the reasons for withdrawal, Yorke and Longden's (2008) findings suggested that students in pre-1992 institutions tended to feel they had made the wrong choice of field of study or lacked commitment. Those from post-1992 HEls tended to cite financial problems, and "issues relating to the learning experience itself".

\section{Reasons for withdrawal}

As indicated above, previous research has pointed to a number of key factors which have been identified as the prime causes for HE students withdrawing from the courses on which they enrolled. Although there are some differences in the terminology and descriptions ascribed to the sources of decisions to withdraw, as well as variations in the ranking or importance given to them, there is general agreement about the reasons.

A DfES funded study conducted by the Institute for Employment Research (Davies and Elias, 2003) found three principal reasons for the decision to withdraw. In order of importance, these were:

1. a mistaken choice of course (24 per cent of respondents);

2. financial problems directly related to participation in higher education (18 per cent);

3. personal problems (14 per cent). 
Analysing these factors in relation to the characteristics of students, it was noted that "financial problems directly related to participation in HE are cited as the most important influence upon withdrawal by male students" (Davies and Elias, 2003: p iv). Financial problems and personal problems were also more likely to be mentioned by those aged over 21. However, for the following sub-groups, mistaken choice of course was categorised as the main reason:

- females;

- those aged 21 or under;

- those who applied through clearing

- those who withdrew during or after the first year.

It was not surprising that the fact that the course did not meet the entrants' expectations was strongly evident among those who had secured their place through clearing: "sixty per cent of those who applied through clearing indicated that the course was not as interesting as they had expected" (compared to 48 per cent who applied through a different route) (Davies and Elias, 2003: p iv). Inadequate or insufficient careers advice and not having visited the institution prior to entry were cited frequently as deficiencies in applicants' preparation for HE.

Davies and Elias (2003) compared their findings to the reasons for drop-out identified in HESA statistics at the time - these cited 'personal' reasons and academic failure as the key factors. Around the same time, the National Audit Office report (2002) had pointed to the following reasons being important:

- lack of preparedness of higher education;

- changing personal circumstances or interests;

- financial matters;

- the impact of undertaking paid work; and

- dissatisfaction with the course or institution.

This comparison is interesting as it highlights the difficulties of categorising reasons for withdrawing from HE. For example, to what extent does Davies and Elias' 'mistaken choice of course' overlap with the NAO's 'lack of preparedness of higher education' or 'dissatisfaction with the course or institution'?

While the Davies and Elias study is important, the data on which it was based is now somewhat dated. Data was collected from a HEFCE database of 16,400 potential 'withdrawers' from 1996/7 and 1998/9 cohorts. Clearly, the significant changes which have affected HE in the UK since that time, notably the introduction of tuition fees and the development of the widening access and participation agenda, detract further from the study's current relevance. Furthermore, the response rate, at around 10 per cent, was acknowledged as being low. The authors also recognise that there was response bias, with a higher proportion of respondents being female than was true of the total 
population. Moreover, the data was collected through postal questionnaires, rather than via interviews, which would have offered the chance to probe individuals' responses.

Perhaps the most influential research on 'drop out' in the UK has been that undertaken by Mantz Yorke, Visiting Professor at Lancaster University. During the 1990s, in similar fashion to the Davies and Elias study, he undertook a quantitative study of 2,151 fulltime and sandwich students who had withdrawn between 1994 and 1996. The response rate achieved was 32 per cent. Yorke (1997) identified the five most significant reasons for student non-completion generally as:

- incompatibility between the student and institution;

- lack of preparation for the higher education experience;

- lack of commitment to the course;

- financial hardship; and

- poor academic progress.

In a subsequent paper which compared the findings of his study and that of Davies and Elias (Yorke, 2003), Yorke points up the similarities in the findings, in terms of the reasons given for withdrawal, as indicated in the following table. The lists are ranked, with the reasons most frequently cited at the top. It can be seen that, while there are differences in the rankings, there is some degree of agreement in the findings.

\begin{tabular}{ll}
\hline Yorke (1999) & Davies \& Elias (2003) \\
Wrong choice of field of study & Wrong choice of course \\
Academic difficulties & Financial problems \\
Financial problems & Personal problems \\
Poor quality of the student experience & Academic difficulties \\
Unhappiness with the social environment & Wrong choice of institution \\
Dissatisfaction with institutional provision &
\end{tabular}

Source: Yorke, 2003

Elaborating further on his findings, Yorke (2003) suggested that older students were only half as likely as younger students to indicate that they felt they had made the wrong choice of course. However, they were more likely to cite financial problems as affecting their HE experience. This was consistent with the Davies and Elias (2003) findings. The study also included a number of part-time students (328), who tended to cite problems with the demands placed on them by work commitments, dependants, and financial problems as being significant issues (Yorke, 2003). 
There is an emphasis in the literature on students feeling uncomfortable with their course or with their surroundings as a prime contributor to drop-out. Yorke (2008) states that:

"Those with lower prior knowledge indicated consistently stronger influence on leaving, compared with their better-informed peers. The difference was particularly marked in respect of their levels of commitment and of financial concern"

Importantly, Yorke and Longden have recently conducted a large scale study of students' first year experience in HE (Yorke and Longden, 2008). A survey was conducted in spring 2006 of just over 7,000 first year students across nine subject areas in 23 UK HEls. A further study was then made of 462 students who had withdrawn in the first year. A distinct advantage of this study is the ability to make direct comparisons with Yorke's earlier work, and therefore detect trends. The overall conclusion drawn by the authors is that "the issues raised by the respondents show considerable similarity to those raised by the respondents to the survey conducted for HEFCE a decade ago" ( $p$ 44).

Drawing on a range of recent studies of student withdrawal, Staying the course: The retention of students in higher education (National Audit Office, 2007) produced the following list of "common reasons for withdrawal". It can be seen that the seven main reasons given align fairly well with the studies cited above. Crucially, however, the examples given under each category not only provide examples of what may be subsumed within them, but also alert the reader to the variety of factors which may underlie a specific 'main reason'. The inclusion of 'to take up a more attractive opportunity' recognises a key message emanating from Quinn et al's (2005) study that withdrawal is not necessarily for negative reasons.

\section{Common reasons for students' withdrawal from courses}

\section{Personal reasons}

- Student may fall mentally or physically ill, or a longstanding problem may worsen

- Homesickness is thought to be a common cause of very early withdrawal, especially among young women and students from rural areas

- Balancing domestic obligations against study requirements - for example, childcare or elder care arrangements may collapse

\section{Lack of integration}

- An absence of positive ties means students fail to 'bond' with the institution and are more easily deterred when another issue arises

- Students 'drift away' without institutions knowing why or when they have withdrawn

- Difficulty in fitting in socially — students from deprived areas may feel culturally isolated 


\section{Dissatisfaction with course/institution}

- The student may feel bored or otherwise dissatisfied with the standard of tuition

- The course may not lead to the professional accreditation they were seeking

\section{Lack of preparedness}

- The course content may not be what the student was expecting

- Students may not have the study skills in place for success or realise the extent to which progress will rely on self-direction

- Students may not realise the level of commitment required to succeed

- The level of the course may be too difficult

- Late applications for Disabled Students' Allowances may mean the student does not have the support and equipment in place at the start of term

\section{Wrong choice of course}

- Students may not have researched their choice deeply, especially if entering late

- Students may be channelled into inappropriate subjects (especially working class men)

- Lack of information about higher education can lead to stereotypical choices of course and institution (especially students from disadvantaged areas)

- Working class students may lack the confidence to change course or institution

\section{Financial reasons}

- Students no longer pay tuition fees up-front, but they may still incur debt

- The student may struggle to balance working while studying. Working in excess of 15 hours a week has been found to reduce chances of progression

- Benefits and allowances may not come through in time to meet financial commitments

- Fear of debt, more than actual levels of debt, may be an issue for some students

- Limited funds may mean students from disadvantaged backgrounds cut short their studies

- Students may have unrealistic lifestyle expectations which drives them into debt and early leaving (especially young men)

\section{To take up a more attractive opportunity}

- Attending the university or college may allow a student to achieve their career goals without necessarily completing the course

- Taking time out to travel

- Late realisation of academic interests or career goals 
(National Audit Office, 2007: p46)

In common with other studies, the National Audit Office report placed emphasis on the fact that, more often than not, there was more than a single cause of a student's withdrawal - "students withdraw from courses for a variety of inter-related reasons" ( $p$ 46). Earlier, Yorke (2003) had highlighted the complexity of issues which may lead to the decision to withdraw, and, in so doing, exposed the difficulties of attributing drop-out to individual causes, stating that "retention correlates inversely with social class and mature entry, and positively with A Level points".

\section{Factors affecting students' decision to withdraw}

\section{Motivation}

In addition to the main reasons highlighted, Yorke (2003) pointed to a number of "other unmeasured factors" that could determine whether students choose to withdraw from their course. These included: motivation; a 'malleable' self-theory, whereby it is recognised that individuals' intelligence, rather than being fixed, is susceptible to development ${ }^{6}$; self-efficacy, and "whether the student has a sense of 'belonging' (both academically and socially) in an institution" (Yorke, 2003: p 3).

Approaching the issue of student withdrawal from a different perspective, Charlton et al (2006), a team of psychologists, have emphasised the importance of distinguishing between two types of motivation to explain the phenomenon. They differentiate 'intrinsic' motivation, which relates to studying for its own sake, because of a deep-seated interest, from 'extrinsic' motivation, which is derived from studying in order to secure better job prospects or lifestyle. Referring to Davies and Elias' findings, they conclude that "recent evidence suggests that lack of intrinsic motivation may be an important factor in withdrawal, a nationwide survey of withdrawing students showing that almost half agreed with the statement 'the course was not as interesting as I had expected"' ( $p$ 33). They also cite Ozga and Sukhnandan's (1998) findings, which emphasised the importance of students being on their preferred course, as a factor aiding retention, to support this idea.

Methodologically, Charlton et al's (2006) study is interesting, because, rather than relying on the collection of data from students about reasons for withdrawal after the decision to withdraw has been made, it adopted a 'prospective' approach. This entailed identifying demographic and psychological factors among students on entry to HE, with a view to predicting the likelihood of their withdrawing.

\section{Integration}

As far as the theoretical underpinning of the literature on student withdrawal is concerned, Tinto's model (Tinto, 1975; 1993) has been influential. The model, which has its roots in Durkheim's model of suicide (Draper, 2003), is founded on the belief that a student's

\footnotetext{
${ }^{6}$ see Dweck, C. S. (1999).
} 
propensity to drop out is highly dependent on their levels of two types of integration: academic integration, in terms of how they cope with the academic demands of their course; and social integration, in terms of their interaction with peers and others who may be able to provide support. Draper (2003), while acknowledging the commonsense appeal of the theory, is sceptical about whether it can be supported by empirical evidence.

Another development of this model is that proposed by Thomas (2002a), whose work is grounded in Bourdieu's theory of 'habitus', which she describes as referring to "the norms and practices of particular social classes". Thomas identified seven potential topic areas for explaining drop-out: academic preparedness; the academic experience (including assessment); institutional expectations and commitment; academic and social match; finance and employment; family support and commitments; and university support services. This was refined in another paper (Thomas, 2002b) to suggest that there were five spheres of integration "within higher education that are significant in terms of the relationships and sense of belonging that students experience, and subsequently their persistence or otherwise in higher education.

i). The academic sphere - the teaching, learning and assessment system - which promotes academic integration

ii). The economic sphere - the student financial support system - which promotes economic integration

iii). The social sphere - the peer system - which promotes social integration

iv). The support sphere - the student services system - which promotes personal integration

v). The democratic sphere - the governance and representation system - which promotes democratic integration"

(Thomas, 2002b, p 4)

It is important to note that a main focus of Thomas' work is the widening access agenda. However, when she states that there is "a wide range of interacting personal and social attributes, as well as institutional practices, which impact on both retention rates and performance" (Thomas, 2002a, p 426), this is consistent with the view of Yorke and Longden (2008), as well as other contributors to the debate, that "withdrawal was the result of a combination of circumstances, rather than attributable to a single cause" ( $p$ 25).

\section{Social capital}

Thomas also relates this perspective to the concept of social capital, especially in relation to creating access to higher education to individuals from "socially excluded communities". She argues that those from non-traditional backgrounds who enter HE are more likely to remain there if they have support from social networks and contacts, whose values and norms they area able to share. Thomas (2002a) refers to "academic, social and cultural inclusiveness" as requirements for students to feel that they fit in.

Finance 
Crucially, although money is often assumed to be the most pertinent factor, there is little hard evidence to support this view. Moreover, the most recent studies (Yorke and Longden, 2008) suggest that it is declining in importance as a factor for inducing student withdrawal.

Bennett et al (2007) undertook a study of "rapid student exit from business-related undergraduate programmes" and point to a scarcity of research focussing on "early walkers', who leave within the first few days or weeks of their courses. The study found that, within the university in which the research was conducted, in 2004, twelve per cent of the intake had left within thirty days, and an additional seven per cent within the next four weeks. An interesting point made by the study is that the reasons for withdrawal will differ, dependent on when it takes place. Thus, they contend that dropping out for financial reasons is more likely to occur later in the academic year. For the "early walkers', the reasons are more likely to relate to initial impressions or experiences of the institution, whether it be the course, the accommodation, the travelling involved, or inability to establish friendship networks. Other factors which they cite as being important, and which are flagged up in the literature, include:

- Individual academic self-concept - where the academic requirements were felt to be daunting

- Commitment to being a student - where they are not strongly motivated to undertake a course of learning

- Student's presuppositions - where they have underestimated the academic demands

\section{Positive reasons for withdrawal}

The study by Quinn et al (2005) is prominent in the debate about student withdrawal and its findings resonated with respondents in the consultation phase, in terms of the factors which are considered to be important in effecting drop-out. The research was targeted at young people under the age of 25 who were from working-class backgrounds, and was undertaken in four 'new' (ie post-1992) universities in disadvantaged areas in England, Scotland, Wales and Northern Ireland. As well as in-depth interviews with 67 drop-out students, data was gathered at each of the four universities from a wide range of stakeholders, current and 'drop-out' students, lecturers, and support staff (Quinn et al, 2005).

A key finding of the study was that support was given to the idea that withdrawal was not necessarily a disaster:

"Although 'drop out' can be traumatic, many students do not regard their decision to leave early as negative. On the contrary, they gain positive experiences from having attended university, if only for a very short time, and this can help them to move forward with their lives."

(Quinn et al, 2005: p 37) 
This is an important study, because of its qualitative exploration of the factors which affect the decisions of working class students to continue in, or withdraw from HE, as well as its key conclusion that "the view that students who 'drop out' are permanently 'lost' to education is not supported by this research" (Quinn et al, 2005: p 46). However, caution should be urged in placing too much weight on the findings, due to the very specific and somewhat narrow target group which was the focus of the study.

Nonetheless, the suggestion that withdrawal need not be treated as a 'disaster', in terms of putting off those who withdraw from the HE experience from considering returning to HE in the future, is offered support by Yorke and Longden (2008) when they compare their findings from a survey of first year students undertaken in 2005-2006 with those of a similar study undertaken ten years previously (Yorke, 1999). Their conclusion is that:

"The data from the HEFCE study of a decade ago suggested that nearly three-quarters of full-time students who had discontinued a programme of study either had returned, or intended to return, to study at the same or another institution. The responses to the present study $(N=462)$ paint a very similar picture".

(Yorke and Longden, 2008: p43)

Withdrawal as a process

In Basit et al's (2006) study of minority ethnic trainees withdrawing from initial teacher training courses, emphasis was placed on the need to regard withdrawal as a process, rather than as an event. Accordingly, this process was broken down into four components:

- Attendance before withdrawal - it was shown that 37.2 per cent of withdrawal occurred within the first semester, with a further 25.6 per cent taking place after one year;

- Timing of withdrawal in relation to key phases of training - the vast majority of withdrawal occurred after either the first (45.9 per cent) or second (41.2 per cent) teaching placement;

- Discussion of the decision to withdraw - family (76 per cent) and representatives of the initial teacher training Institution (58 per cent) were the most frequently mentioned sources of discussion prior to the decision to withdraw;

- Regrets for the decision to withdraw - just over a fifth (22 per cent) stated that they regretted their decision to withdraw.

(see Basit et al (2006), pp 396-398)

Clearly, the fact that this study focused on teacher training, with a greater likelihood for participants to be graduates, often with family responsibilities, means that the findings are not directly applicable to the circumstances of those withdrawing from most degree courses. However, the notion of the process involved, with indications of when, and by 
whom, interventions may be helpful to the student, has resonance for wider considerations of student withdrawal.

\section{When withdrawal occurs}

The study of initial teacher training trainees referred to above raised the issue of the timing of student withdrawal. Previous work undertaken by Arad Consulting (Arad, 2007) indicated that, traditionally, drop-out rates are at their highest during the Christmas break period. Therefore, issues that prompt students to drop out often develop relatively quickly during the first semester of the academic year. Furthermore, the study concluded that students from all backgrounds, including those from widening access groups, drop out of higher education as a result of a number of different issues. Clearly, the role of institutions in identifying individual students who may be at risk of dropping out and responding to their concerns can be of paramount importance.

Bennett et al also focused on student withdrawal as a phenomenon which tends to occur relatively early in the academic year, and proposed a model of early leaving, wherein "early exit decisions are influenced by 'moments of truth' experienced during the first couple of weeks or so of a person's university experience" (Bennett et al, 2007: p 115). This is an interesting study, although the sample for the empirical research was not representative - "two thirds of the interviewees were male, $43 \%$ were African and $40 \%$ of Indian sub-continent heritage" ( $p$ 119) - and the focus was 'early walkers' in "business-related undergraduate degree programmes in a post-1992 university".

Yorke and Longden (2008) found that those who dropped out early in the course more frequently mentioned problems with accommodation, difficulty in making friends and lack of support from other students. Those who left at the Christmas break tended to feel that the course was not what they had expected. Those who left later were more inclined to cite difficulties relating to their study skills, the lack of relevance of the course, or having failed assessments (Yorke and Longden, 2008: p 21).

The assumption within much of the literature that the first term is the time when the majority of decisions to withdraw are taken is challenged by the National Audit Office report (2007). Based upon the time when students are recorded, by the HEl, as having withdrawn, it was found that most students had withdrawn in the summer term, "around the traditional examination time" (National Audit Office, 2007: p21). It is conceded within the report that, in some cases, this may reflect the fact that only when they failed to take the examination were they recorded as having withdrawn - rather than when they actually withdrew.

This uncertainty about the accuracy of the data which is collected in relation to student withdrawal has been the subject of criticism levelled at HEls for the inadequacy of their data. A recent report from the Quality Assurance Agency stated that "only a small minority of institutions have developed completely effective systems for gathering data and created a culture in which this data is fully exploited at both routine and strategic levels" (QAA, 2008). Without this data, robust evidence of when withdrawal is likely to occur is difficult to find. 


\section{Institutional Responses}

Clearly, the propensity for students to withdraw from HE can be mitigated by the actions of HEls. The National Audit Office report stated that "the sector has access to a wide range of advice on good practice in retention, although we found that there is relatively little evaluation of the impact and transferability of practice" (National Audit Office, 2007; p 10). Two key recommendations emanating from this study were for HEls to begin:

- "getting to really know their students and how, generally, they feel about their particular course of study and the culture and amenities offered in the institution"; and

- "developing a more positive approach to retention related activities that recognises how they can also improve student success, and so attract students to take up services who might otherwise not do so."

(National Audit Office, 2007; p 10)

The first of these acknowledges that difficulties arise for many entrants to HE from having to adapt to a culture and an experience with which they are not familiar. It also implicitly recognises the need for HEls to establish a rapport with their students. The second recommendation highlights the importance of providing student support.

For adequate support for students to be provided, emphasis has been placed on the commitment of HEls. Thomas and Yorke (2003) identified the following circumstances as being conducive to appropriate institutional responses by HEls:

- an institutional climate supportive in various ways of students' development, that was perceived as 'friendly';

- an emphasis on support leading up to, and during, the critically important first year of study;

- $\quad$ an emphasis on formative assessment in the early phase of programmes;

- a recognition of the importance of the social dimension in learning activities;

- a recognition that the pattern of students' engagement in higher education was changing, and the preparedness to respond positively to this in various ways.

\section{HEl initiatives}

Peter Morgan of the University of Bradford School of Management, in a Briefing paper on student retention, provided a summary of the areas on which HEls have focused their efforts to enhance student retention. The main points of his analysis are set out below:

- Pre-enrolment actions - the key point Morgan makes here is the need to 'manage expectations', in order that HE entrants have a reasonably accurate picture of what they will encounter in HE. Examples of practices which may be employed include: 
- Giving accurate information, possibly through online chatrooms and other mechanisms;

- Selecting wisely, by focusing recruitment on those who will be able to cope with the demands of $\mathrm{HE}$;

- University summer schools to prepare entrants for HE;

- A friendly contact identified to provide support;

- Careers advice and guidance

- Student Support (Practical, Emotional and Skills development) and Guidance at University - as noted in the discussion of the consultation findings, adequate and appropriate student support is widely regarded as the key to aiding retention of students. Particular aspects proposed by Morgan include:

- Induction schemes

- Study skills development

- Personal tutor systems

- Advice on managing personal finances

- Peer-assisted learning

- Virtual learning environments

- Teaching, assessment and learning issues - Morgan notes Tinto's (1993) emphasis on education as a key component of student support. The two main areas cited by Morgan are:

- Assessment, with feedback being crucial to this process

- Curriculum and workload review, in order that students are able to manage their studies

- Facilitating Integration into life in higher education. This would include enabling students to establish support networks, especially among peers

- Group assignments may assist this process

- Process issues - by this is meant mechanisms or research which HEls can undertake to identify potential problems and enable appropriate student support to be put in place, including:

- Identifying 'at risk' students

- Information collection, use and dissemination

- Staff development - this may involve the development of procedures for data collection, listening and counselling skills, and awareness of retention issues;

- Cultural issues - this entails developing an organisational culture which recognises and responds to the needs of students.

(Derived from Morgan, undated) 


\section{Advice and guidance}

As Morgan advocated above, careers advice and guidance, both at the pre-entry stage, and after enrolling in HE, is vital in ensuring that entrants' choice of course is appropriate and in providing support once they have embarked on their HE course. The inadequacy of the advice and guidance which students had been offered prior to applying for HE was also cited by Quinn et al (2005) as a shortcoming in some HEls.

A study of the delivery of careers education, information and guidance within $\mathrm{HE}$ (Maguire, 2005) described a scheme which had been introduced in an English HEl for attracting students who had dropped out of courses back on to full-time courses ( $p 39$ ). As part of the review process, potential applicants could access advice and guidance from the Careers Service. It was also claimed that it had extended the role of the Careers Service within the university.

\section{Data collection}

Bowen et al (2005), focused on the relationship between regular attendance at lectures, seminars etc and student retention. They also pointed to the inadequacy of the data which is collected within HEls, and which can lead to students 'silently withdrawing', in the sense that the absence of attendance monitoring data means that little is known about them. The response to this situation at the University of Glamorgan, which is where the team is based, was the development of Uni-Nanny, which is an electronic attendance monitoring system. In Bowen et al's study, it was found that students welcomed the increase in data collection and monitoring and were more motivated to attend lectures. It did not provide any evidence of this process having a positive effect on student retention.

\section{Curriculum development}

Ruth Taylor (2005), from the Robert Gordon University, has highlighted the way in which curriculum development can enhance an HEl's capacity to retain students, through enquiry-based learning (EBL). In a study of student attrition on a pre-registration nursing programme, Taylor describes how the introduction of EBL groups, facilitated by the students' personal tutor, who is able to establish a sufficiently close relationship with the students to identify problems as they arise, has had the effect of enhancing the confidence and motivation of students.

\section{Re-thinking student withdrawal}

In the light of the multiplicity of initiatives being implemented by HEls in efforts to address student withdrawal, Quinn et al (2005) allude to a more radical re-thinking on the part of those in $\mathrm{HE}$, which goes beyond tinkering with current arrangements:

"Not talking about exiting and re-entering higher education reinforces the idea that movement and change are not the norm and are problematic. It is 
also counter-intuitive for those students who know well that early withdrawal is commonplace. A lifelong learning model of higher education would require institutions to talk about routes into and out of education and employment, and provide support for them".

(Quinn et al, 2005, pp 62-3)

It is an interesting idea that HEls may be exacerbating the problems faced by new entrants by implicitly denying that withdrawing or changing course can be a positive experience, rather than representing a 'disaster' or some sort of inadequacy on the part of the student. As Quinn et al state, a key element of the notion of lifelong learning is the ability to move into and out of learning activity with relative ease. As the consultations findings suggested, in Wales, lack of concern over course changing has been attributed to the credit system.

On the basis of his findings, Yorke (2008) concludes that what HEls need in order to be classed as being successful, in terms of student retention, can be summarised as:

- commitment to student learning

- commitment to student engagement

- management of student transition

- curriculum seen in terms of social engagement

- emphasis on the importance of the first year experience

- monitoring and evaluation, acting on the evidence

- academic leadership.

(Yorke, 2008)

The STAR system

A recent influential innovation has been the development of the Student Transition and Retention (STAR) project at the University of Ulster (Cook et al, 2005). In a presentation to describe the project, Cook and Richardson (2008) acknowledged that there was a wealth of literature relating to student drop-out, but contended that there was little which focused on addressing the problem. The STAR approach recognises the changes which first year students experience and characterises them as:

- social changes

- work/study/student lifestyle balance

- curriculum changes

- assessment changes

- cope with staff relationship changes

(Cook and Richardson, 2008)

Attributing 'non-continuance' to poor decisions prior to entry and poor preparation or false expectations, they offer the following short-term solutions:

- better information to applicants

- courses should deliver what is advertised 
- developmental teaching of literacy and numeracy

- better communication of standards through formative assessment

- facilitate and encourage students to return

More radically, the longer-term solutions they advocate involve:

- $\quad$ merging full-time and part-time students, in the spirit of modular delivery of courses;

- $\quad$ having post-qualification applications, so that entrants could start at Christmas; and

- " "(designing) a course to suit those who attend it". These recommendations are very much in line with an underpinning belief of the STAR system that "early leaving is an institutional problem but a student's solution". This can also be seen to resonate with Quinn et al's (2005) contention that withdrawal need not necessarily be regarded as a disaster. 


\section{Conclusions and Recommendations}

\section{Student continuation and completion}

Despite significant increases in rates of participation in HE in the UK by students from non-traditional backgrounds, there has been little change in continuation and completion rates in recent years, with those in Wales being slightly higher than the average for the UK. However, the HESA statistics clearly illustrate that HEls in Wales have a student body which differs from that of the UK as a whole, with higher representation from:

$>$ entrants from state schools;

$>$ lower social classes;

> low participation neighbourhoods;

$>$ those studying part-time; and

$>$ disabled people.

Students from these groups have traditionally had higher than average non-continuation rates and lower completion rates. While this partly explains the marginally higher rates in Wales, it is perhaps surprising that they are not considerably higher. Moreover, differential withdrawal rates between HEIs may be attributed to the different characteristics of respective student bodies, especially in terms of the proportions from non-traditional backgrounds. It is important to understand this when assessing the extent of the 'problem' of student withdrawal in Wales.

Another highly significant factor is the recent upward shift in the propensity of Welsh domiciled students to attend HEls in Wales. This may be partly, or largely attributable to the tuition fee policy, with the rebate available to these students making attendance at HEls in Wales a more attractive option, in financial terms, than studying elsewhere in the UK. In terms of gauging the effect of the tuition fee policy on continuation and completion rates is concerned, it is overwhelmingly considered to be too early to pass judgement with any degree of certainty.

\section{Characteristics of non-continuing students}

Student withdrawal tends to be more prevalent among:

- Young males

- Individuals from working class backgrounds

- Those with lower levels of prior attainment

- Those studying certain subjects

- Those attending post-1992 universities 
- Part-time students

Although ethnicity and having a disability had initially been identified as potential contributory characteristics, evidence suggests that these are less important than other factors.

Reasons for withdrawal

The National Audit Office report succinctly summarises what is known about student withdrawal by saying:

"Students leave their courses early for a range of reasons, but there is rarely one single reason why a student gives up their course. Reasons are likely to be a mix of personal (most common), institution and course related, and financial".

(National Audit Office, 2007, p 10)

Understanding this complexity and acknowledging that there is no single overriding factor which leads to student withdrawal is a key feature of the literature.

In terms of the significance of individual factors, Yorke and Longden's recent findings suggest that, for the UK as a whole, finance is diminishing in importance, while inappropriate, or wrong, choice of course and/or institution, and the degree of contact with academic staff are becoming more important. Crucially, the integration of the student, both socially and academically, appears to be the issue which is in most need of attention, both by HEls themselves and by those who provide advice and guidance prior to entry.

\section{Institutional response}

The need to provide adequate support to students, particularly those in the first year of a degree course, is high on the agenda of HEls. It is felt to be incumbent on them to provide such support, especially in the light of the process of widening access.

Initiatives such as the STAR system have been developed, with an explicit recognition of the need for HEls to attempt to understand the fundamental changes which young entrants to HE experience. These can be social, academic and cultural.

Key aspects of institutional responses to student withdrawal include:

- an emphasis on the pre-entry stage, with better provision of information and guidance, the introduction of 'taster' events, and the provision of experience of selfdirected learning;

- the importance of the role of personal tutors; and

- evidence of commitment from HEls to understanding and enhancing student retention. 


\section{Implications for further CRP 2007-2010 research}

At the outset of the literature review of student withdrawal, no firm ideas had been developed about the issues or target groups which should form the focus of any subsequent work under the CRP 2007-2010. The subsequent study, involving the literature search, and, importantly, consultations with key stakeholders, has enabled a number of areas to be proposed as worthy of consideration. Certainly, with the imminent revision of the funding methodology for Higher Education, and rates of student continuation and completion being mooted as factors to be taken into account when the allocation of funding takes place, it is likely that any work undertaken for the CRP 20072010 which addresses the issue of student withdrawal will make a contribution to the process of policy formation.

\section{Student finance}

The role of student finance arrangements in determining levels of take-up of HE opportunities, and subsequent student retention in Wales continues to be an area of interest, for both policy-makers and academic researchers. Arad Consulting has recently completed a study of student finance in Wales, which may shed further light on this issue.

As far as tuition fees are concerned, there appears to be a consensus that, as yet, there is insufficient robust data to reach definitive conclusions about the impact that tuition fees will have on take-up of, or retention in HE in Wales. An interesting factor, however, is the increase in the tendency for Welsh domiciled people to attend HEls in Wales. This is partly, or largely, attributed to the fee remission which is available to these students, and which represents a significant reduction in the cost of accessing $\mathrm{HE}$ - certainly in comparison to attending HEls outside Wales. Therefore, consideration should be given to a study which compares the attitudes to withdrawal from $\mathrm{HE}$ of students who stay in the parental home, and those who re-locate in order to pursue their studies.

\section{Ethnic minority students}

Although some work has started on gaining a deeper understanding of the issues which affect the entry and continuation of ethnic minority students in HE, further investigation of this aspect of access to HE would also be welcomed. As stated in the main body of this report, the study of minority ethnic students and graduates (Connor et al, 2004), and the attendant caveat concerning the significance of factors such as prior educational attainment, subject, gender and age in determining the propensity to withdraw, suggest that withdrawal among this group may not be as problematic as initially indicated. To counter this, it should be emphasised that little is known of the particular issues and circumstances, either individually or in combination, which influence the decision to withdraw. Therefore, a case can be made for undertaking a study of this group.

\section{HE delivered in FE}

The issue of the delivery of HE courses at Further Education institutions is likely to be an increasingly important area for further research, especially in relation to the development 
of Foundation degrees and the increase in the number of institutions being granted degree awarding powers.

\section{Part-time students}

Given the high proportions of people studying on a part-time basis at HEls in Wales, and the fact that discussions about student drop-out tend to be couched in terms of full-time students, a piece of research which focused on part-time students could contribute to a deeper understanding of the HE experience of these students, as well as shedding more light on the reasons for non-continuation and non-completion.

“We know remarkably little about part-time students' experiences”

$$
\text { (Mantz Yorke, April } \left.1^{\text {st }} 2008\right)
$$

The above quotation, from one of the leading authorities on student retention, highlights understanding about part-time students as a notable gap in current knowledge. This may be partly attributable to what is recognised to be a complex area on which to derive information, as described in the NAO report.

"There are particular difficulties with data about part-time students due to the inherent flexibilities in the patterns of study and time taken to complete a course"

(National Audit Office, 2007, p14)

It was noted in the NAO report that, in conjunction with the Performance Indicators Steering Group, HEFCE was undertaking a study of non-continuation and completion among part-time students.

Before embarking on a study of withdrawal among part-time students, however, a number of recent developments need to be taken into account. Firstly, following the Graham Review of Part-Time Study in Higher Education in Wales (Graham, 2006), which considered the potential impact of changes to the system of fees and student support for part-time students, an announcement was made in June 2008 about additional funding which was being made available to part-time students (HEFCW, 2008b).

Another recommendation was that the Graham Review should "ask HEFCW to work with the sector to identify performance indicators specifically appropriate for part-time students" (Brown and Boorman, 2006, p 42). This was to include issues related to progression and completion.

Thus, there is already significant policy interest in part-time students, to which a study undertaken as part of the CRP 2007-2010 could contribute.

It should also be noted that a component of the Futuretrack longitudinal study of 2006 applicants to HE in the UK, which is funded and carried out on behalf of the Higher Education Careers Services Unit (HECSU), will be a longitudinal study of part-time 
students. The focus of the research will be students' career intentions, career development, their employment and training outcomes, and employers' views of their employees studying part-time. Students will be surveyed in 2008 and 2010 . However, the protracted timescale of this study leaves considerable scope for work to be undertaken under the CRP 2007-2010 without fear of duplication.

\section{Students in Years 2 and 3}

As indicated in the consultations, little is known about students who withdraw in Years 2 and 3, and the factors which affect their decisions. The HESA statistics for 2005-06 show that, in Wales, 7.8 per cent of full-time first degree starters did not continue into a second year. Furthermore, only 77.2 per cent of starters were projected to graduate. This leaves a further 15 per cent of starters who are projected to withdraw at some time in their second or third year, or to fail to complete in some other way. The reasons for withdrawal may be different from those which affect first year students. For many, their lifestyle may have changed, having moved out of student accommodation, their workload could be increasing and they may be becoming anxious about their future careers. Furthermore, for some, the demands of part-time employment, which they may need to undertake for financial reasons, may be further detracting from their ability to perform sufficiently well in their studies.

Therefore, consideration should be given to undertaking research which provides insights into the reasons for this post-Year 1 withdrawal. It could be argued that, having successfully completed the first year, but failed to achieve a degree qualification, the damage to individuals' career prospects, and possibly self-esteem and self-confidence may be more severe than is the case of those who drop out during the first year.

\section{Students who are based at home}

It was shown earlier that difficulties in coping with what, for most students, is a range of unfamiliar circumstances, whether it is the city or town where their HEI is located, the experience of living away from home, a requirement for more self-directed learning, or having to establish friendship networks, is believed to be a major underlying factor in many decisions to drop out of HE. It was also stated that there has been an increase in the proportions of students who prefer to be based at home for the duration of their $\mathrm{HE}$ experience, relative to those who move to another locality to attend an $\mathrm{HEI}$. An interesting piece of research would involve studying samples of both types of students, with a view to gaining a deeper understanding of the factors which give rise to students contemplating withdrawal.

\section{Widening access}

Another potential area for further research was the impact of the widening access agenda. In particular, it was felt that the assumption that students who had been attracted to $\mathrm{HE}$ as a result of this policy direction were at greater risk of dropping out should be challenged.

HEI practice to address student retention 
It was also stated that it would be useful to identify good practice in the way in which HEls were addressing the issue of student drop-out and to get to know more about what activities and mechanisms were particularly effective in supporting retention. The relationship between particular $\mathrm{HEl}$ approaches and practices which effected improved student retention and the characteristics of the students who were targeted by these practices would be worthy of consideration. However, a narrowly focused identification of good practice would not necessarily sit well with the objectives of the CRP 2007-2010.

\section{Recommendations for future research}

Although it is slightly premature to be overly prescriptive about the focus of any future CRP 2007-2010 study of student withdrawal, it is likely that research focusing on one or more of the following target groups would make a useful contribution to the current knowledge base and would inform policy-makers:

- those studying part-time, across different types of institutions, age ranges and subject areas;

- $\quad$ BME students;

- $\quad$ students studying HE courses delivered within FE institutions;

- students who withdraw in Years 2 and 3;

- comparative study of students who were based at home and those who had moved away from home to study.

Underpinning whatever group or groups are identified as appropriate for further investigation, it should be borne in mind that there is general consensus that, while there is a plethora of literature which focuses on the issues of withdrawal and retention, we have scant understanding of the complexity of issues which contribute to individuals' decisions to withdraw.

For an issue which is acknowledged to be multi-faceted and complex, in-depth qualitative research would seem to be the most appropriate method of undertaking exploratory work which would offer the prospect of developing a greater understanding of the factors which combine to incite withdrawal, and, crucially, of devising mechanisms to reduce the likelihood of withdrawal. The findings could then inform the development of a wider quantitative study. 


\section{References}

Adnett, N. (2006), "Student Finance and Widening Participation in the British Isles: Common Problems, Different Solutions". Higher Education Quarterly, Vol. 60, No. 4, October, pp 296-311.

Arad Consulting (2007), Evaluation of the widening access activities and the Reaching Wider Initiative in Welsh Higher Education Institutions, Higher Education Funding Council for Wales.

Arulampalam, W., Naylor, R. A., and Smith, J. P. (2007), "Dropping out of medical school in the UK: explaining the changes over ten years". Medical Education, Vol.41, no.4: April, p385-394.

Basit, T. N., Roberts, L., McNamara, O., Carrington, B., Maguire, M. and Woodrow, D. (2006), "Did they jump or were they pushed? Reasons why minority ethnic trainees withdraw from initial teacher training courses". British Educational Research Journal, Vol.32, no.3: June, p387-410

Bennett, R.' Kottasz, R., and Nocciolino, J. (2007), "Catching the early walker: an examination of potential antecedents of rapid student exit from business-related undergraduate degree programmes in a post-1992 university". Journal of Further and Higher Education, Vol.31, no.2: May, p109-132.

Bentley, H. and Allan, J. (2006), "Student drop-out: an investigation into reasons for students leaving bioscience programmes in one new university over a period of five years". Widening Participation and Lifelong Learning, Vol.8, no.3: December, p40-46.

Bowen, E., Price, T., Lloyd, S. and Thomas, S. (2005), "Improving the Quantity and Quality of Attendance Data to Enhance Student Retention", Journal of Further \& Higher Education; November, vol.29 (4) p375-385.

Broecke, S. and Hamed, J. (2008), Gender Daps in Higher Education Participation: An Analysis of the Relationship between Prior Attainment and Young Participation by Gender, Socio-Economic Class and Ethnicity. DIUS Research Report 0814.

Brown, N. and Boorman, S. (2006), Collection of quantitative data not available from public sources. Independent Review of Part-Time Higher Education Study in Wales (Graham Review) Strand 2.

Cartney, P. and Rouse, A. (2006), "The emotional impact of learning in small groups: highlighting the impact on student progression and retention", Teaching in Higher Education, Vol.11, no.1: January, p79-91. 
Campbell, T. A. and Campbell, D. E. (2007), "Outcomes of mentoring at-risk college students: gender and ethnic matching effects". Mentoring and Tutoring, Vol.15, no.2: May, p135-148.

Challen, D. (2005), To teach or not to teach: trainees' responses to the challenges faced during initial teacher training: a summary. Paper presented at the British Educational Research Association Annual Conference, University of Glamorgan, 14-17 September 2005.

Charlton, J. P., Barrow, C., and Hornby-Atkinson, P. (2006), "Attempting to predict withdrawal from higher education using demographic, psychological and educational measures", Research in Post-Compulsory Education, Vol.11, No.1: March, p31-47.

Connor, H., Tyers, C., Modood, T. and Hillage, J. (2004), Why the Difference? A Closer Look at Higher Education, Minority Ethnic Students and Graduates. Research Report RR 552. London: DfES.

Cook, A., Rushton, B. S., McCormick, S.M. and Southall, D.W. (2005), Guidelines for the Management of Student Transition: The STAR (Student Transition and Retention) Project. University of Ulster, Coleraine, Northern Ireland.

Cook, T. and Richardson, H. (2008), Strategies for Student Transition and Retention. Presentation to 'Staying the course: The retention of students in higher education' conference, April $1^{\text {st }}$. Organised by the Higher Education Academy, the National Audit Office, and the Higher Education Funding Council for England.

Davies, R. and Elias, P. (2003), Dropping Out: A study of early leavers from Higher education. DfES Research Brief 386, December.

Draper, S.W. (2003), Tinto's Model of Student Retention [www document] URL http://www.psy.gla.ac.uk/ steve/localed/tinto.ht ml Accessed April 2003.

Dweck, C. S. (1999), Self-theories: their role in motivation, personality, and development. Philadelphia, PA: The Psychology Press.

Eastwood, D. (2008), 'High drop-out rate? Hardly. We have an excellent record'. The Guardian, $26^{\text {th }}$ February.

Fitzgibbon, K. and Prior, J. (2006), "Students' early experiences and university interventions - a timeline to aid undergraduate student retention". Widening Participation and Lifelong Learning, Vol.8 (3): December, p17-27.

Forsyth, A. and Furlong, A. (2003), Losing out? Socioeconomic Disadvantage and Experience in Further and Higher Education. Bristol: The Policy Press/JRF. 
Foster, K. (2002), Libraries and Student Retention: Report of the Services and Learning Evaluation Project. University of Teesside.

Glanville, K., Green, A. and Hannan, A. (2004), Widening participation, retention and attainment in higher education: an institutional case study of student experience. This paper is based on a conference paper entitled "Widening participation in HE: issues of retention and performance" presented at the Education, Participation and Globalisation Prague 2004Conference, 20-22 May 2004.

Gorard, S., Smith, E., May, H., Thomas, E., Adnett, N., and Slack K., (2006), Review of Widening Participation Research: addressing the barriers to participation in higher education. HEFCE: Bristol.

Graham, H. (2006) Independent Review of Part-Time Higher Education Study in Wales. Cardiff. Welsh Assembly Government.

HEFCW (2008a), Welsh Higher Education Statistics 2004/05. HEFCW website.

HEFCW (2008b), Additional Support for Part-Time Students 2008/09. HEFCW Circular W08/23HE. June.

HEFCW (2007), HEFCW Annual Report 2006-2007. Higher Education Funding Council for Wales.

Henderson, S. E. (2003), "Strategic Enrolment Management”. Paper presented at "Students in the Consumer Age: Recruitment and Retention Issues" Association and University Administrators Conference, London 29-30 January.

HESA (Higher Education Statistical Agency) (2004), Performance Indicators in HE in the UK. London: HESA.

Howieson, C., Ozga, J. and Provan, F. (2003), Student retention in the University of Edinburgh: final report. University of Edinburgh. Centre for Educational Sociology.

Hughes, G. (2007), "Using blended learning to increase learner support and improve retention”. Teaching in Higher Education, Volume 12, Number 3, June, pp 349-363 (15).

James, H. (2007), "Non continuation rates of full-time students: do benchmarks deliver?" Paper presented to the 2007 HEFCW Reaching Wider National Conference, University of Wales, Gregynog, March $5^{\text {th }}$.

Johnston, V. and Simpson, O., (2006), "Retentioneering" higher education in the UK: attitudinal barriers to addressing student retention in universities". Widening Participation and Lifelong Learning, Vol.8 (3): December, p28-36.

JRF (2005), Rethinking working-class drop out from university. Findings: Informing change. December. Joseph Rowntree Foundation. 
Leitch, S. (2006), Prosperity for all in the global economy - world class skills. Final Report. HM Treasury.

Leys, J. (1999), Student retention: everybody's business, paper for the 'Educators and Planners: Symphony or Discord' AAIR Conference. December $1^{\text {st }}-3^{\text {rd }} 1999$.

Maguire, M. (2005), Delivering Quality: Quality assurance and delivery of careers education, information and guidance for learning and work within higher education. DfES and the Association of Graduate Careers Advisory Services (AGCAS).

Martinez, P. (2001), Improving Student Retention and Employment: What do we know and what do we need to find out? Learning and Skills Development Agency.

May, S., Hodgson, D. and Marks-Maran, D. (2005), Feet under the table: students' perceptions of the effectiveness of learning support provided during their first year of study on health and social care programmes. Paper presented at the Society for Research into Higher Education Conference, University of Edinburgh, 13-15 December 2005.

McCausland, W. D., Mavromaras, K. and Theodossiou, I. (2005), "Explaining student retention: the case of the University of Aberdeen", Widening Participation and Lifelong Learning, Vol.7, (3): December, p24-26.

McGivney, V. (1996) Staying or leaving the course: non completion and retention, Adults Learning, 7, 133-135.

Metcalf, H. (2005) "Paying for University: the Impact of Increasing Costs on Student Employment, Debt and Satisfaction". National Institute Economic Review, 191, January, pp106-117.

Morgan, P. (undated), Briefing Paper on Student Retention. University of Bradford School of Management.

National Audit Office (2007), Staying the course: The retention of students in higher education, July. London, The Stationery Office.

National Audit Office (2002), Improving student achievement in English higher education London, The Stationery Office.

Ozga, J. and Sukhnandan, L. (1998), 'Undergraduate Non-Completion: Developing an Explanatory Model', Higher Education Quarterly. Vol. 52, No.3, July, pp 316-333.

Parmar, D. (2005), "Other", "personal" and "unknown": an institutional approach to exploring the reasons behind withdrawal statistics. Paper presented at the British Educational Research Association Annual Conference, University of Glamorgan, 14-17 September 2005. 
Pugh, G., Coates., G and Adnett, N. (2005), 'Performance Indicators and Widening Participation in UK Higher Education'. Higher Education Quarterly, Volume 59, No. 1, January 2005, pp 19-39.

QAA (2008), Outcomes from institutional audit: Progression and completion statistics. The Quality Assurance Agency for Higher Education.

Quinn, J. (2005), "Rethinking working class "drop out" from university", Widening Participation and Lifelong Learning, Vol.7,(3): December, p27-31.

Quinn, J., Thomas, L., Slack, K., Casey, L., Thexton, W. and Noble, J. (2005), From life crisis to lifelong learning: Re-thinking working-class 'drop out' from higher education. Joseph Rowntree Foundation.

Rees, G. and Taylor, C. (2006), "Devolution and the Restructuring of participation in HE in Wales”. HE Quarterly - Oct. 06, Vol. 6, Issue 4, pp 293-418.

Rees, T., Bell, D., Bruce, T., Davies, D., Humphreys, R., Jenson, G, McGinley, D., Reynolds, S., Richards, K., Singh, R., Smith, E., Williams, F., Woodall, M., and WynneJones, E. (2005), Fair and Flexible Funding: A Welsh Model to Promote Quality and Access in Higher Education. Final Report of An Independent Study into the Devolution of the Student Support System and Tuition Fee Regime in Wales (The Rees Review) Main Report, Cardiff: Welsh Assembly Government.

Sideridis, G D. (2007), "Persistence of performance-approach individuals in achievement situations: an application of the Rasch model". Educational Psychology, Vol.27, No.6: December, p753-770.

Smith, J. and Naylor, R.A. (2001), 'Dropping out of university: a statistical analysis of the probability of withdrawal for UK university students', Journal of the Royal Statistical Society, Vol. 164, No. 2, pp. 389-405.

SQW (2007), Study of the Role of Foundation Degrees in Wales. Report to the Higher Education Funding Council for Wales.

Taylor, R (2005), “Creating a connection: tackling student attrition though curriculum development", Journal of Further and Higher Education, Vol.29, (4): November, p367374.

Taylor, C. and Gorard, S. (2005), Participation in Higher Education, Wales: report for the independent study into the devolution of the student support system and tuition fee regime.

Thomas, L. (2002a), 'Student retention in higher education: the role of institutional habitus'. Journal of Educational Policy, Vol. 17, No. 4, pp 423-442. 
Thomas, L. (2002b), Building social capital to improve student success. Paper presented to BERA Conference, University of Exeter, 2002.

Thomas, L. and Quinn, J. (2007), First generation into higher education: an international study. Maidenhead: SRHE and Open University Press.

Thomas, L. and Yorke, M. (2003), "Improving the retention of students from lower socioeconomic groups", Journal of Higher Education Policy and Management, Vol.25, No. 1, pp 63-75.

Tinto,V. (1975), "Dropout from Higher Education: A Theoretical Synthesis of Recent Research", Review of Educational Research, Vol. 45, pp.89-125.

Tinto, V. (1993), Leaving college: rethinking the causes and cures of student attrition [2nd Edition]. Chicago: University of Chicago Press.

UUK (2006), Part-time Students in Higher Education - Supporting Higher-level Skills and Lifelong Learning. Policy Briefing. Universities UK. October.

Walkup, V. J. (2006), "I'm not stopping until I've done it and I'm taking the children with me": a report upon research into the needs and experiences of students who are mothers (S.W.A.Ms) returning to higher education. Paper presented at the British Educational Research Association Annual Conference, University of Warwick, 6-9 September, 2006. This paper is an extended version of a paper presented at the 35th Annual SCUTREA Conference, University of Sussex, 5-7 July, 2005.

Watson, D., (2006), How to think about widening participation in UK higher education. HEFCE: Bristol.

Welsh Assembly Government (2002), Reaching Higher: Higher Education and the Learning Country. A strategy for the higher education sector in Wales. March.

Woodley, A. (2003), Conceptualising student drop-out in higher education. Open University. Open University initiative in Open and Distance Learning.

York Consulting (2004), Evaluation of Foundation Degrees. Report for Department for Education and Skills (DfES).

Yorke, M. (1999), Leaving early: undergraduate non-completion in higher education. London: Falmer.

Yorke, M. (2000), "The rear-view mirror tells a story: subject area differences in undergraduate non-completion and their implications for the improvement of learning in higher education", in Rust, C. (ed) Improving student learning through the disciplines. Oxford: Oxford Centre for Staff and Learning Development, pp.398-409. 
Yorke, M. (2003), Why students leave early in higher education in the UK. Open University initiative on Student Retention in Open and Distance Learning.

Yorke, M. (2007), The first-year experience: successes and challenges. Paper prepared for the third seminar in the series on mass higher education in UK and international contexts, organised by the Centre for Research in Lifelong Learning, Glasgow Caledonian University and others, and held on 29-30 May.

Yorke, M. (2008), The First Year Experience Study 2005-07. Presentation to 'Staying the course: The retention of students in higher education' conference, April $1^{\text {st }}$. Organised by the Higher Education Academy, the National Audit Office, and the Higher Education Funding Council for England.

Yorke, M. and Longden, B. (2005), Significant figures: performance indicators and 'league tables'. London: Standing Conference of Principals.

Yorke, M. and Longden, B. (2007), The first-year experience in higher education in the UK (Report on Phase 1 of a project funded by the Higher Education Academy)

Yorke, M. and Longden, B. (2008) The first-year experience in higher education in the UK. Final Report. The Higher Education Academy.

Yorke, M., Bell, R., Dove, A., Haslam, E., Hughes-Jones, H., Longden, B., O'Connell, C., Typuszak, R. and Ward, J. (1997), Undergraduate non-completion in higher education in England [Report 97/29]. Bristol: Higher Education Funding Council for England.

Yorke, M., Barnett, G., Evanson, P., Haines. C., Jenkins, D., Knight, P., Scurry, D., Stowell, M. and Woolf, H. (2005), Mining institutional datasets to support policy making and implementation. Journal of Higher Education Policy and Management, 27 (2), pp.285-98. 


\title{
Annex A: Consultation Topic Guide
}

\author{
DELLS CRP 2007-2010
}

HE Literature Review Consultations Topic Guide

$18 / 2 / 08$

\section{Remit and scope of department/branch/organisation}

a) Please outline the remit and scope of your department/branch/organisation, and, in particular, the relevance of issues relating to student drop-out and/or early course changing among HEls in Wales

b) Does your department/branch/organisation maintain data on student drop-out and/or early course changing?

c) Are comparisons made with English/Scottish/European data?

d) Please describe the sources of data which are currently available to determine the extent of student drop-out and/or early course changing

\section{Student drop-out and non-completion}
a) To what extent does student drop-out constitute an issue of concern?
b) What are perceived to be the main underlying causes/factors?
c) What is the evidence base for focusing on this issue?
d) What is your perception of trends within Wales?
e) How does this differ between HEls in Wales?
f) What are the reasons for these variations?

\section{Early course changing}
a) To what extent does student early course changing constitute an issue of concern?
b) What are perceived to be the main underlying causes/factors?
c) What is the evidence base for focusing on this issue? 
d) What is your perception of trends within Wales?

e) How does this differ between HEls in Wales?

f) What are the reasons for these variations?

\section{Key issues}

a) What are the defining characteristics of those students who are most prone to student drop-out and/or early course changing? (eg prior attainment, social class, type of $\mathrm{HEl}$, location, Welsh/non-Welsh students)

b) To what extent, if any, have the widening participation and widening access agendas impacted on student drop-out and/or early course changing?

c) Is student drop-out and/or early course changing more prevalent among students in particular subject or disciplinary areas?

d) Does it tend to occur at certain times of the academic year (eg end of the first term)

e) What are the factors which differentiate between HEls in rates of drop-out/course changing (eg pre- and post-1992 HEls)

f) To what extent have changes in student finance arrangements impacted on rates of drop-out/course changing?

g) What do you anticipate to be the effect of tuition fees on future rates of dropout/course changing?

h) What are the implications for advice and guidance systems of increasing rates of drop-out/course changing?

i) What factors are of particular interest/concern in explaining student drop-out and/or early course changing (in each case, probe re scale/intensity etc)?:

- Mistaken choice of course

- Inadequate or inappropriate advice and guidance

- Financial problems

- Personal problems

- HEl policies and practices(eg student support)

- Flexibility of the system

- Other (specify)

\section{Relevant policy initiatives/programmes}

a) Please identify and describe the key policy initiatives/programmes targeted at student drop-out and/or early course changing 
b) What are the particular issues they are seeking to address?

c) Who is responsible for providing/delivering them?

d) What evaluation has been undertaken or is planned?

e) What have been the main findings and impact of the evaluations?

f) What criteria are used to assess the extent to which the programmes/initiatives have been successful?

\section{Institutional responses}

a) Is there a common approach across HEls in Wales to addressing the issues of student drop-out and/or early course changing?

b) What are the main elements of HEls' policies and practices towards student drop-out and/or early course changing?

c) What mechanisms are in place for early identification of students at risk of dropping out and/or early course changing?

d) Are there any HEls in Wales which have approaches which are particularly worth further investigation, because of their innovativeness or success?

e) Do you have contact names for individuals within HEls in Wales?

\section{Relevant research undertaken in recent years}

a) Please identify (and provide copies where appropriate) of relevant research undertaken in recent years, detailing the specific issues addressed, methodology adopted, and key findings

b) How and in what way, have they informed policy direction in the areas of student drop-out and/or early course changing?

c) Please identify (and provide copies where appropriate) existing material which has focused on the areas of student drop-out and/or early course changing

d) Please give details of current or planned research which seeks to address these issues 


\section{Policy development}

a) What are the main strands of current policy direction in relation to student drop-out and/or early course changing?

b) Are any shifts in this policy direction anticipated?

c) What specific programmes are under consideration?

d) What data is routinely collected to monitor/evaluate the impact of programmes?

e) What measures, if any, are taken to elicit the perspectives and opinions of

- HEl senior staff

- Current students

- Prospective students

\section{Gaps in knowledge}

a) Please identify what you consider to be the main gaps in knowledge which are inhibiting policy development in relation to student drop-out and/or early course changing?

b) What specific issues need to be examined further?

c) Are there any particular target groups about which more needs to be known, through further study? (Please specify and expand)

\section{Further contacts}

a) Could you identify other individuals who could provide valuable insights for the study?

b) Are there other sources of data which could be examined? 


\section{Annex B: Systematic Review}

The basic elements of the EPPI-Centre 'systematic review' are:

1. Systematic Reviews are transparent about how their conclusions are generated

2. A 'protocol' sets out how the review is to be conducted before the work starts

3. Exhaustive searches are undertaken to find as much as possible of the relevant research

4. The review methods are made explicit

5. Potential users of the review are involved

6. The findings of sound research are synthesized

The following protocol was adopted to determine what evidence was appropriate for inclusion in the review.

- Focus - the prime focus of the search for literature and other evidence documents were the issues of drop-out and early course changing among those enrolling in Higher Education. This included data on course completion and qualification attainment. Reports and data focusing on related topics, such as the widening participation and increasing participation agendas, student finance, student support, advice and guidance, and students' satisfaction with their HE experience, were also explored. The key criterion here was the relevance of the material to the focus of the review.

- Timing - given the importance attached to the shifting HE policy environment, there was clearly a need to concentrate on published material which has been produced in recent years, in order to take account of the effects of: a) the widening participation agenda; b) the increase in the proportions of successive cohorts of school-leavers entering HE; c) the expansion of access to HE to groups not traditionally well represented in the sector; and d) the introduction of tuition fees. Although no specific time frame was stipulated, precedence was accorded to evidence which had emerged in the last ten years.

- Geographical coverage - the focus was predominantly on data and reports from the UK (and especially any which is specifically or partially targeted on HEls in Wales). However, relevant material from further afield have been reviewed where it was considered appropriate. For example, Vincent Tinto, who is one of the leading figures in the development of conceptual models of student progress, conducted research in the United States from the mid-1970s (Tinto, 1993). Although his empirical findings may be of little relevance for developing an understanding of the position of students in HEls in Wales in the present day, Tinto's theoretical perspective and model of student retention continue to provide points of reference for current debates.

- Type of study - evidence derived from both quantitative and qualitative sources were deemed eligible for inclusion in the review. Also, as well as reports based on substantive, objective pieces of research, evidence and policy documents have been included from, for example, HEFCW and individual HEls. 
- Quality - a principal concern in evaluating the appropriateness of sources which have been identified will be the quality of the data on which they are based.

Thus, factors such as the methods of obtaining data, sample size and representativeness, the reliability of the findings, the objectivity and transparency of the process of analysis, and the presentation of findings, will be key considerations. 
